\title{
Aceites esenciales modificadores de perfiles de fermentación ruminal y mitigación de metano en rumiantes. Revisión
}

\section{Ruminal fermentation modification and methanogenesis mitigation by essential oils from plants. Review}

\author{
Laura Alicia Polin Raygozaa, Alberto Muro Reyesa,b, Luis Humberto Díaz Garcíaa
}

\begin{abstract}
RESUMEN
Debido a la preocupación mundial que se tiene sobre el calentamiento global por la producción de gases de efecto invernadero y el impacto que tiene el metano producido por el sector agropecuario, se han usado antibióticos como mitigantes de la producción de metano; sin embargo estos han sido prohibidos en Europa desde enero de 2006 y se espera que en los próximos años sea impedido en otros continentes. Esta prohibición generó la investigación de compuestos alternativos sintéticos o naturales con capacidad antimicrobiana que no generen resistencia en los microorganismos pero que ejerzan efectos similares a los antibióticos. Se han evaluado nitrocomponentes, taninos, saponinas, y recientemente otros componentes secundarios de las plantas como los aceites esenciales (AE). Existe una gran cantidad de AE sin embargo; sólo han sido evaluados en promedio 70 de estos, y sus componentes activos, a los que se les atribuye la modificación de la fermentación ruminal o mitigante de metano. La mayoría de los trabajos que mencionan efectos en la fermentación ruminal y mitigación del metano se han realizado in vitro, en algunos casos con resultados importantes, y recientemente se han comenzado a generar datos de investigaciones in vivo con la inclusión de la evaluación de parámetros productivos y de salud animal. El presente tiene como objetivos principales mostrar y discutir los resultados y avances de las investigaciones referentes a AE in vitro e in vivo, en referencia a la inclusión de estos y las respuestas sobre los principales parámetros de fermentación ruminal, mitigación de la producción de metano en el rumen, así como también el rumbo que debieran seguir futuras investigaciones.
\end{abstract}

PALABRAS CLAVE: Aceites esenciales, Metano, Rumiantes.

\begin{abstract}
Methane production in ruminant livestock systems has been controlled traditionally through antibiotic use. However, these have been banned in Europe since 2006 and will soon be banned on other continents. In response, research has focused on identifying synthetic and natural compounds with antimicrobial properties that do not foster microorganism resistance. Plant secondary components such as essential oils are receiving increasing attention. To date, only 70 essential oils and their main active principles have been tested to determine their effect on ruminal fermentation modification and/ or methane mitigation. Most studies addressing these phenomena have been in vitro, and some report significant modification and/or mitigation action. In vivo studies including productive parameters have only recently been carried out. An overview is done of in vitro and in vivo research into the effects of essential oils on the main parameters of ruminal fermentation, methane mitigation, production performance and immune condition, and suggestions made for future research.
\end{abstract}

KEY WORDS: Essential oils, Methane, Ruminants.

Recibido el 17 de febrero de 2012. Aceptado el 18 de agosto de 2012.

a Universidad Autónoma de Zacatecas, Unidad Académica de Medicina Veterinaria y Zootecnia. Carretera Panamericana Zacatecas-Fresnillo, Km. 31.5 Calera de Víctor Rosales, Zacatecas, 98500, México. Tel. (53)4789851255, Fax. (52)4789850202. amurey@hotmail.com. Correspondencia al segundo autor.

b University of Veterinary Medicine, Institute of Animal Nutrition, Vienna, Austria.

Agradecimiento a CUMEX por el apoyo económico para la realización de estancia posdoctoral en la Universidad de Medicina Veterinaria de Viena, Austria. 


\section{INTRODUCCIÓN}

La combustión de los energéticos ha incrementado aceleradamente la producción de gases con efecto invernadero, sobre todo en las últimas décadas. En conjunto el sector pecuario con sistemas de producción de leche o carne de rumiantes principalmente, contribuye al calentamiento global con las emisiones de metano a la atmosfera. De acuerdo a la FAO, la ganadería contribuye con hasta $\sim 37 \%$ del total de las emisiones antropogénicas de metano $\left(\mathrm{CH}_{4}\right)$, en su mayoría provenientes de la fermentación entérica de los rumiantes(1). Otro factor importante es que las emisiones entéricas de metano representan pérdidas de energía entre 2 al $12 \%$ de la ingesta de energía bruta en los rumiantes, dependiente del nivel del consumo de alimento y tipo o composición de la dieta $(2,3,4)$. Se ha mencionado que una disminución de metano del $25 \%$ en los rumiantes, puede resultar en incrementos de $1 \mathrm{~L}$ de leche al día en vacas altas productoras, y de $75 \mathrm{~g} /$ $d$ de incremento de peso en bovinos productores de carne(5).

Los aditivos químicos usados para disminuir la producción de metano en rumiantes han sido principalmente antibióticos, los cuales además armonizan la fermentación ruminal, mejoraran el consumo y eficiencia alimenticia, maximizan el crecimiento corporal, e incrementan la producción de leche y carne, pero el uso de estos ya no es permitido en Europa desde enero de 2006(6). A consecuencia de esto se intensifican las investigaciones sobre el uso de agentes antimicrobianos de origen sintético o natural como promotores del crecimiento; ejemplo de estos son los compuestos o componentes metabólicos secundarios de las plantas.

Existen algunas plantas que generalmente no son consumidas por el ganado, y que contienen compuestos bio-activos como los AE (aceites esenciales) entre otros, que poseen propiedades antimicrobianas y pueden ser incluidos en la alimentación animal con el objetivo de mejorar la utilización de los alimentos y la salud

\section{INTRODUCTION}

Fuel combustion has increased greenhouse gas production during recent decades. Livestock production, primarily ruminant milk and meat systems, contributes notably to atmospheric methane emissions. According to the FAO, cattle ranching accounts for up to $\sim 37 \%$ of total anthropogenic methane $\left(\mathrm{CH}_{4}\right)$ emissions, mostly from enteric fermentation in ruminants(1). These same emissions represent an energy loss of 2 to $12 \%$ of ruminants' gross energy intake depending on feed intake rates and diet type and composition $(2,3,4)$. Indeed, a $25 \%$ reduction in methanogenesis could result in a $1 \mathrm{~L}$ per day increase in milk production in high output cows or a $75 \mathrm{~g}$ per day increase in weight gain in beef cattle(5).

Antibiotics are the main chemical additives used to control methanogenesis in ruminants. They have the added advantages of harmonizing ruminal fermentation, improving feed intake and efficiency, maximizing body growth, and increasing milk and meat production; nonetheless, their use has been prohibited in Europe since 2006(6). In response, research has intensified on synthetic or natural antimicrobial agents as growth promoters, among them plant secondary metabolic compounds and components.

Cattle consume a relatively limited number of plants, although many plant species could be beneficial additions to cattle diets. Among these are plants that produce bioactive compounds, such as essential oils (EO), that have antimicrobial properties and could be included in cattle diets to improve feed efficiency and overall animal health(7). The extracts of some plants are known to exhibit antimicrobial properties versus a broad spectrum of microorganisms such as protozoa, bacteria, fungi and viruses $(8,9,10)$. The mitigating effect of $E O$ in methanogenesis has been evaluated, but they were also found to attenuate total volatile fatty acids (VFA). Essential oils tested for this purpose include those from thyme, oregano, cinnamon, 
animal(7). Los extractos de algunas plantas posen propiedades antimicrobianas contra gran variedad de microorganismos como protozoarios, bacterias, hongos y virus $(8,9,10)$. Algunos estudios han evaluado el uso de los AE y su efecto en la mitigación de la producción de metano, pero en estos también se ha observado atenuación de los ácidos grasoso volátiles (AGV) totales. Ejemplos de $A E$ utilizados con este propósito son aceites de timol, orégano, canela, ajo, rábano, entre muchos más; estos mencionados han demostrado reducir la producción de metano in vitro. En algunos casos la inhibición de metano se logró con dosis elevadas(>300 mg/L de cultivo ruminal), y en otros se disminuyó por la baja producción de AGV o cambio en la proporción de estos mismos, o la disminución en la digestión del alimento. El objetivo del presente trabajo fue concentrar y examinar la producción científica relacionada con $\mathrm{AE}$, dosis de inclusión, y el efecto sobre los parámetros de fermentación ruminal en estudios in vitro e in vivo.

\section{DEFINICIÓN Y FUNCIÓN DE LOS ACEITES ESENCIALES}

Los AE son componentes secundarios de las plantas, generalmente de naturaleza volátil $(9,11,12)$. El término esencial deriva de la palabra "esencia", lo cual significa que se puede oler o degustar(10). Se caracterizan de acuerdo a sus multitudes composiciones químicas, naturaleza y propiedades bio-activas. La concentración y tipo de AE en las plantas varía por especie y segmento de la planta principalmente, pero también se han reportado diferencias dependientes de la región geográfica y estación de cosecha(13-17). La función principal de los $A E$ es brindarle a la planta protección contra agentes estresantes abióticos y bióticos, y en algunas ocasiones atraer a otros organismos para favorecer la polinización y dispersión de sus semillas(18).

\section{CARACTERÍSTICAS QUÍMICAS DE LOS} ACEITES ESENCIALES

Los principios activos que se encuentran en los $A E$ se clasifican dentro de dos grupos garlic, radish and many more. All these EO have been reported to reduce methanogenesis in vitro, although in some cases this was only attained at high doses (>300 mg/L rumen culture). In other cases, it was lowered due to reduced VFA production, changes in VFA proportions or reduced feed digestion. The present review covers the literature addressing $E O$, effective doses and their effects on ruminal fermentation and methanogenesis in vitro and in vivo.

ESSENTIAL OILS: DEFINITION AND FUNCTION

Essential oils are secondary components in plants and are generally volatile $(9,11,12)$. The term "essential" derives from "essence", in the sense of to smell or taste(10). They are characterized by their multiple chemical compositions and bioactive properties. Essential oil type and concentration in plants mainly varies by species and plant segment, but differences have been reported between geographic regions and harvest seasons(13-17). The role of EO is to protect plants against abiotic and biotic stressors, and sometimes to attract organisms that promote pollination and/or seed dispersion(18).

\section{CHEMICAL CHARACTERISTICS}

The active principles of EO are classified into two groups: terpenoids (monoterpenoids and sesquiterpenoids); and phenylpropanoids. Each group originates in different primary metabolism precursors and is synthesized via different metabolic routes in plants. Terpenoids are the more numerous and diverse of the two with approximately 15,000 described to date(12). The group name derives from the fact that they have a basic structure of five carbons $\left(\mathrm{C}_{5} \mathrm{H}_{8}\right)$, commonly called an isoprene unit. Phenylpropanoids are less common although some plant species contain them in large quantities. Compounds in this group have three carbons bonded in six-carbon aromatic rings and derive largely from the aromatic amino acid phenylalanine. This is synthesized by the 
químicos; terpenoides (monoterpenoides y sesquiterpenoides) y fenilpropanoides. Estos dos grupos se originan de diferentes precursores del metabolismo primario y son sintetizados por vías metabólicas diferentes en las plantas. Los terpenoides son el grupo más numeroso y diversificado, se han descrito aproximadamente 15,000(12). Se denominan así porque derivan de una estructura básica de cinco carbonos $\left(\mathrm{C}_{5} \mathrm{H}_{8}\right)$, comúnmente denominada unidad isopreno. Los fenilpropanoides son menos comunes, pero algunas plantas los contienen en cantidades altas, poseen cadenas de tres carbonos ligados a anillos aromáticos de seis carbonos y derivan en su mayoría de la fenilalanina (aminoácido aromático) sintetizado por la vía metabólica de Shikimato, la cual es sólo funcional en microorganismos y plantas(19). Aunque se ha investigado bastante a los $A E$ en diversas plantas, aún no se ha indagado con precisión en lo referente a cómo el estrés induce en las plantas su producción, o cambios en la composición y concentración de estos $(20,21,22)$.

Los isoprenos $\left(\mathrm{C}_{5}\right)$ son los más comúnmente presentes en las plantas; isopentenil difosfato y dimetilamina difosfato, básicamente constituidos por terpenos y pertenecen al grupo de los terpenoides(23). Ejemplo de isoprenos son el limoneno, timol, carvacrol, linalol, carvon. Aunque los terpenos y fenil-propenos dominan en los $A E$, el aceite de ajo en particular contiene gran cantidad de órgano-sulfuros, como el dialil disulfuro y el dialil trisulfuro originados de la glutamil-cisteína(24-27). En la mayoría de los casos los AE están compuestos por un principio activo dominante y en menor cantidad los otros de características semejantes, como ejemplo el aceite de ajo en el que predomina el dialil disulfuro y cantidades menores de alicina, entre $\operatorname{otros}(13,23)$.

\section{PRINCIPALES PROPIEDADES BIOLÓGICAS}

Los extractos de las plantas que contienen los llamados componentes secundarios de las plantas han sido tradicionalmente usados en la salud humana(28). Los efectos positivos en la
Shikimato route, which is functional only in microorganisms and plants(19). Extensive research has been done on EO in diverse plant species, although little detailed attention has been given to how stress induces plants to produce them, or to change their composition and concentration $(20,21,22)$.

Isoprenes $\left(\mathrm{C}_{5}\right)$ are most common in plants. Isopentenyl, diphosphate and dimethylamine diphosphate are constituted mainly of terpenes and belong to the terpenoids group(23). Other isoprenes include limonene, thymol, carvacrol, linalool and carvone. Although terpenes and phenyl-propenes predominate among the EO, garlic oil has a particularly high content of organo-sulphurs such as diallyl disulphur and diallyl trisulphur which originate from glutalylcysteine(24-27). Most EO are composed of a dominant active principle and smaller quantities of other components with similar characteristics; for example, diallyl disulphur predominates in garlic oil which also contains smaller amounts of allicin, among other components $(13,23)$.

\section{MAIN BIOLOGICAL PROPERTIES}

Plant extracts containing what are called secondary components have been used in human health for millennia(28). They are known to have positive effects on cardiovascular diseases, some tumors, inflammatory processes and generally in diseases where free radical proliferation is a serious threat(29-33). Perhaps the most widely known and important property of many plant extracts is their antiseptic action, known since ancient times $(34,35)$.

\section{ANTIMICROBIAL ACTION MECHANISMS}

Terpenoids and phenyl-terpenoids exercise action primarily against Gram+ bacteria via interactions with the cell membrane $(15,35,36)$. These compounds accumulate in the double lipid layer of the bacterial cell, occupying spaces between the fatty acid chains. This causes morphological changes in membrane structure and resulting fluidification and expansion $(36,37,38)$. The loss in membrane stability results in ion 
salud son en enfermedades cardiovasculares, algunos tumores, procesos inflamatorios, y en general en enfermedades donde la proliferación de radicales libres representan un grave peligro(29-33), aunque la acción más importante de estos compuestos es la antiséptica, conocida desde la antigüedad( 34,35$)$.

\section{MECANISMOS DE ACCIÓN ANTIMICRO- BIANA}

Los terpenoides y fenil-terpenoides ejercen su acción contra las bacterias Gram+ principalmente, mediante interacciones con las membranas celulares de éstas $(15,35,36)$. Se acumulan en la doble capa lipídica de la bacteria, y ocupan espacios entre las cadenas de los ácidos grasos, por lo que causan de esta manera cambios morfológicos en la estructura de la membrana, y como resultado fluidificación y expansión $(36,37,38)$. La pérdida en la estabilidad de la membrana da como resultado fugas o pérdidas de iones, lo que causa un decreciente gradiente iónico transmembranal, y aunque la bacteria puede contrarrestar estos efectos, el costo energético es elevado y provoca al final un crecimiento lento o su muerte $(36,38,39)$. Otros efectos antimicrobianos son la capacidad para coagular algunos componentes de la membrana que se cree son mediante procesos de desnaturalización de proteínas y actividad en enzimas principalmente $(40,41,42)$. Ejemplo de esto, es la alicina, que se ha demostrado que interactúa con proteínas y aminoácidos que contienen grupos sulfhídricos (-SH), mecanismo asociado a el diallil-sulfuro que contiene la alicina $(43,44)$.

Se ha observado también que los mecanismos de acción de los AE son más efectivos en bacterias Gram+, en las cuales actúan directamente con los componentes hidrofóbicos de la membrana celular, aunque esto puede variar dependiendo del principio activo presente en el $A E$ y el tamaño de éste(45-48). Algunos AE tienen actividad en contra de bacterias Gramy Gram+, hongos, parásitos y virus, dependiendo esto del perfil de componentes activos o su actividad sinérgica(49-52). leaks and losses, lowering the transmembranal ionic gradient, and, although bacteria can counteract these effects, the energetic cost is high and eventually leads to retarded growth or death $(36,38,39)$. Among other antimicrobial effects is the capacity to coagulate some membrane components, probably mainly through protein denaturation and enzyme activity $(40,41,42)$. For example, allicin is known to interact with proteins and amino acids containing sulphydric (-SH) groups, a mechanism associated with the diallyl-sulphur group in allicin $(43,44)$.

Essential oil action mechanisms are more effective against Gram+ bacteria. They act directly on cell membrane hydrophobic components, although this varies depending on an EO's active component and its size (45-48). Depending on their active components profile and/or their synergic activity, some EO have activity against Gram- and Gram+ bacteria, fungi, parasites and viruses(49-52).

\section{EFFECT OF EO IN RUMEN MICROBIAL POPULATION}

Rumen bacteria. Many EO inhibit ammoniacal nitrogen-producing bacteria, thus lowering amino acid deamination, mainly in diets without high protein content $(53,54,55)$. These EO do not change the total number of viable bacteria, just the proportion of bacterial groups. However, in vitro studies using doses (e.g. $400 \mu \mathrm{g} / \mathrm{ml}$ thymol) higher than commonly used in the literature did find a decrease in total microorganism count $(56,57)$.

Rumen protozoans. The effects of EO on protozoan populations apparently depend on the EO administered, the dose and the animal model used. No changes in protozoan population have been reported in studies of sheep and dairy cattle administered feed containing 110 and $150 \mathrm{mg} / \mathrm{d}$ of an EO mix, respectively $(58,59)$. Neither were effects observed on ciliate protozoans in dairy cattle used as rumen liquid donors in response to a dose of $500 \mathrm{mg}$ cinnemaldehyde/L rumen liquid(60). Fennel extract also does not modify protozoan 
EFECTO DE LOS AE EN LA POBLACIÓN MICROBIANA RUMINAL

Bacterias ruminales. Se ha reportado que los $\mathrm{AE}$ inhiben a las bacterias productoras de nitrógeno amoniacal, decreciendo así la desanimación de los aminoácidos principalmente en dietas que contienen cantidades no muy altas de proteína $(53,54,55)$. También se ha observado que el número total de bacterias viables no es afectado, es decir cambian solamente las proporciones de grupos bacterianos, pero en estudios in vitro donde se han incluido dosis altas, como por ejemplo 400 microg/ml de timol en comparación con las comúnmente reportadas en la literatura, sí provocan descenso en el número total de microorganismos $(56,57)$.

Protozoarios ruminales. En experimentos realizados con ovinos y ganado productor de leche a los que se les incluyó en la ración alimenticia diaria una mezcla de $A E$ a dosis de 110 y 750 mg/d respectivamente, no se observaron cambios en la población de protozoarios $(58,59)$. Tampoco se han encontrado efectos sobre los protozoarios ciliados en vacas productoras de leche utilizadas donadoras de líquido ruminal cuando se administra cinemaldehido con dosis de $500 \mathrm{mg} / \mathrm{L}$ de fluido ruminal(60). El extracto de hinojo tampoco modificó la población de protozoarios(61). Otros no observaron cambios en la población de protozoarios cuando se suministró aceite de rábano encapsulado a razón de $20 \mathrm{~g} / \mathrm{kg}$ de MS, o aceite de rábano en dosis de $1 \mathrm{~g} / \mathrm{d}$ en novillos castrados de la raza Holstein de entre 6 y 7 meses de edad, así como tampoco cuando se suministró $1 \mathrm{~g} / \mathrm{kg}$ MS a vacas productoras de leche $(53,62)$. A diferencia de lo anterior otros autores han reportado que la alimentación con $200 \mathrm{~g} / \mathrm{kg}$ de MS de menta (Mentha piperita) de novillos Holstein decrece el número total de protozoarios y el número de Entodiniun, Isotricha y Diplodinium. También se ha observado que el aceite de clavo decrece en número total de protozoarios, afectando a los pequeños Entodinium y Holotrichos, pero no a los Entodinium de mayor tamaño(61). Otros populations(61). Radish oil is reported to have no effect on protozoans when administered at $20 \mathrm{~g} / \mathrm{kg}$ DM in capsules, at $1 \mathrm{~g} / \mathrm{d}$ in castrated Holstein bullocks between 6 and 7 mo of age and at $1 \mathrm{~g} / \mathrm{kg} \mathrm{DM}$ in dairy cattle $(53,62)$.

In contrast, other studies have found clearly negative effects on protozoans with some EO. Administering of mint (Mentha piperita) to Holstein bullocks at $200 \mathrm{~g} / \mathrm{kg}$ DM lowered the total protozoan count and Entodinium, Isotricha and Diplodinium counts. Clove oil lowers the total number of protozoans, particularly affecting small Entodinium and Holotrichos, but not larger Entodinium(61). Cinnemaldehyde at doses from 0.4 to $1.6 \mathrm{~g} / \mathrm{d}$ in beef bullocks had no effect on protozoans but did lower Isotrica, Dasitrica and Entodinium counts(63). Inclusion of anise extract in feed for bullocks at a dose of $2 \mathrm{~g} / \mathrm{d}$ lowered both Holotrichos and Entodiniomorph populations(62). Use of mint at $200 \mathrm{~g} / \mathrm{d}$ in dairy cattle is reported to lower the total protozoan population(64). Finally, addition of $1 \mathrm{~g} / \mathrm{d}$ anethole in $2 \mathrm{~g}$ anise extract in the feed of beef bullocks lowered Holotrichos and Entodiniomorph counts, although this could be an indirect effect of alterations in nutrient degradability(65).

\section{EO AND RUMINAL FERMENTATION}

Volatile fatty acids. A number of in vivo studies have been done evaluating the inclusion of different EO and their doses on total volatile fatty acid (VFA) production in different ruminant species (Tables 1, 2 and 3). Reports exist of both small decreases in total VFA concentration $(61,66,67)$, and significant declines, especially at high EO concentrations $(68,69)$. Slight increases in total VFA concentration have been reported in only a very few studies. Increases have been reported with inclusion of $200 \mathrm{mg}$ cinnemaldehyde/ $\mathrm{kg} \mathrm{DM}(70), 250 \mathrm{mg}$ oregano oil/kg DM(71), and $1.5 \mathrm{ml}$ of an EO mixture (thymol, limonene and guaiacol)/L (in vitro)(72).

The effect of EO on total VFA concentration depends on diet type or substrate. For example, 
estudios observaron que el cinemaldehido a dosis de 0.4 a $1.6 \mathrm{~g} / \mathrm{d}$ en novillos productores de carne no afecta el total de protozoarios pero sí a los Isotrica, Dasitrica y Entodinium(63). La inclusión de extracto de anís en novillos con dosis de $2 \mathrm{~g} / \mathrm{d}$ decrece el número de Holotrichos y Entodiniomorfos (62). Se ha reportado que el uso de menta, $200 \mathrm{~g} / \mathrm{d}$ en bovinos productores de leche ha logrado decrecer el total de protozoarios(64). En contraste la inclusión de 1 $\mathrm{g} / \mathrm{d}$ de anetol en $2 \mathrm{~g}$ de extracto de anís a novillos productores de carne, mostró disminución en el conteo de Holotrichos y Entodiniomorfos, sin embargo eso puede ser un efecto indirecto de alteración en la degradabilidad de nutrientes(65).

\section{AE Y FERMENTACIÓN RUMINAL}

Ácidos grasos volátiles. Algunas de los investigadores reportan una pequeña disminución en la concentración total de $\operatorname{AGV}(61,66,67) ;$ otros mencionan disminuciones significativas especialmente cuando se emplean concentraciones altas de aceites esenciales $(68,69)$. Sólo unos cuantos estudios mencionan ligeros aumentos en la concentración total de AGV con inclusión de cinemaldehido en dosis de 200 $\mathrm{mg} / \mathrm{k}$ de $\mathrm{MS}(70)$, y en dosis de $250 \mathrm{mg} / \mathrm{kg}$ de MS de aceite de orégano(71). También se ha reportado que el uso de mezclas de $A E$ (timol, limoneno y guayacol) en dosis de $1.5 \mathrm{ml} / \mathrm{L}$ (in vitro), incrementan los AGV totales(72). La respuesta a la inclusión de los aceites esenciales sobre la concentración total de AGV depende del tipo de dieta o substrato, en dosis de 75 $\mathrm{mg} / \mathrm{d}$ por vaca de una mezcla de aceites esenciales en vacas lecheras alimentadas con ensilado de alfalfa no hubo disminución de los AGV, pero si cuando se alimentaron con ensilado de maíz, lo cual puede deberse a las diferentes características nutrimentales de los forrajes utilizados(58).

Se reporta que la relación de acetato-propionato incrementa $(68,73,74)$, aunque en otros estudios no se han encontrado diferencias (69,71). Algunos $\mathrm{AE}$ tienen impacto en la producción de AGV at a dose of $75 \mathrm{mg}$ of an EO mixture per day in dairy cows, those fed alfalfa silage exhibited no decrease in VFA while those fed corn silage did. This was probably due to the nutritional characteristics of the different forages(58).

Some EO negatively impact VFA production at low $\mathrm{pH}$, suggesting that the status of EO molecules as dissociated or undissociated depends on $\mathrm{pH}$. At a slightly acid $\mathrm{pH}$, EO are undissociated and therefore hydrophobic, allowing them to interact more easily with microbial membranes, modify the rumen microbial population and therefore VFA production and proportion(75). As with other ruminal fermentation parameters, the EO's active principle profile influences VFA amount and proportion(76). Modifications to total VFA content and VFA proportion impact methane production profiles, particularly if acetate is reduced and propionate increased. Any change in VFA parameters can therefore positively or negatively affect methane production. Some studies have found an increase in the acetate-propionate ratio with addition of $\mathrm{EO}(68,73,74)$, while others have found no differences $(69,71)$.

Ammoniacal nitrogen. Nitrogen-generating bacteria represent only $1 \%$ of the rumen bacterial population, but they possess deamination activity $(54,88)$. Reduced ammoniacal nitrogen $\left(\mathrm{NH}_{3}-\mathrm{N}\right)$ concentration in the rumen in response to EO may favor greater protein flow into the small intestine(77). As mentioned previously, some EO inhibits nitrogen-generating bacteria and therefore lower protein deamination. Using 30 and $300 \mathrm{mg}$ oregano $\mathrm{oil} / \mathrm{L}$, these bacteria were lowered by up to $25 \%(58,75)$. In an in vitro study, administration of cinnamon oil at 7.8 to $15.6 \mathrm{mg} / \mathrm{dL}$ (equivalent to an EO dose of 0.3 to $3,000 \mathrm{mg} / \mathrm{L}$ ) lowered ammoniacal nitrogen content, whereas anethole (3 g/L), carvacrol (300 mg/L) and carvone (300 $\mathrm{mg} / \mathrm{L}$ ) did not have this effect(79). In another study, guaiacol reduced ammoniacal nitrogen content by $31.4 \%$ at $5 \mathrm{mg} / \mathrm{L}$ and by $16.6 \%$ at $5,000 \mathrm{mg} / \mathrm{L}$, but no effect was observed with limonene and thymol $(50 \mathrm{mg} / \mathrm{L})$, and 
cuando el pH es bajo, sugiriendo que el estatus de las moléculas de los aceites esenciales disociados o no disociados depende del $\mathrm{pH}$, esto debido a que a un $\mathrm{pH}$ ligeramente ácido los AE se encuentran en un estado no disociado y por lo tanto en forma hidrofobica, lo cual les permite interactuar de forma más fácil con las membranas microbianas y por tanto modificar la población ruminal y la proporción y producción de AGV(75). Al igual que en otros parámetros de fermentación ruminal, el perfil de los principios activos que contenga el $A E$ influye vanillin and eugenol $(500 \mathrm{mg} / \mathrm{L})^{(80)}$. As occurs with other responses, the effects of EO on nitrogen-generating bacteria depend on diet contents, specifically protein type and content(77).

\section{METHANE PRODUCTION PROFILES}

Results demonstrating how EO inclusion in diets affects rumen methane production are limited and inconsistent. In some cases, rumen methane production has been estimated based on the relationship of methane to decreased

Cuadro 1. Efecto de la adición de diferentes aceites esenciales y dosis sobre el consumo, producción de leche, metano y ácidos grasos volátiles totales en vacas lecheras, en diferentes estudios. Estimación de las diferencias porcentuales con respecto al tratamiento testigo

Table 1. Effect of different essential oils and doses on dry matter intake, milk production, methanogenesis and total volatile fatty acids proportion in dairy cattle in selected studies. Percentages are the differences versus a control treatment

\begin{tabular}{|c|c|c|c|c|c|c|}
\hline Essential oil & $\begin{array}{l}\text { Dose } \\
\mathrm{g} / \mathrm{d}\end{array}$ & $\begin{array}{l}\mathrm{DMI} \\
(\%)\end{array}$ & $\begin{array}{c}\text { Milk production } \\
(\%)\end{array}$ & $\begin{array}{c}\text { Methane } 1 \\
\text { production (\%) }\end{array}$ & $\begin{array}{c}\text { Total } \\
\text { VFA (\%) }\end{array}$ & Ref. \\
\hline EOM & 0.32 & -1.52 & -3.76 & ND & ND & (90) \\
\hline EOM & 0.64 & -1.01 & -2.13 & ND & ND & $(90)$ \\
\hline EOM & 0.96 & -0.50 & -2.25 & ND & ND & (90 \\
\hline EOM & 2.0 & -2.62 & -0.87 & -2.74 & -7.63 & (100) \\
\hline EOM & 0.75 & -0.57 & -5.9 & 5.20 & 5.09 & (73) \\
\hline EOM & 0.75 & $-1-12$ & -0.5 & -1.32 & -10.31 & (73) \\
\hline Cinnemaldehyde & 1.0 & -0.43 & 1.78 & 0.89 & 0.49 & (111) \\
\hline Garlic oil & 5.0 & -1.44 & 3.10 & -2.24 & -1.47 & $(87)$ \\
\hline Juniper oil & 2.0 & -0.96 & 1.37 & 2.82 & -0.62 & (87) \\
\hline Diallyl disulphur & 13.88 & 1.71 & -2.31 & ND & ND & (108) \\
\hline Diallyl disulphur & 10.02 & 1.29 & -2.64 & ND & ND & (110) \\
\hline Diallyl disulphur & 3.36 & -5.08 & 1.63 & ND & ND & (110) \\
\hline Carvacrol & 6.35 & -2.62 & 1.46 & 0.60 & -2.49 & (105) \\
\hline EOM & 1.2 & 7.19 & 4.77 & ND & ND & (104) \\
\hline EOM & 1.87 & -3.84 & 1.03 & -7.27 & 2.48 & (106) \\
\hline EOM & 3.96 & -3.84 & -3.67 & -6.13 & 2.90 & (106) \\
\hline EOM & 6.13 & -2.19 & -1.37 & -1.17 & 0.77 & (106) \\
\hline EOM & 1.0 & -5.10 & 0.08 & ND & ND & $(90)$ \\
\hline EOM & 0.5 & -2.51 & -0.06 & -3.93 & -0.92 & (109) \\
\hline EOM & 10.0 & -2.92 & -4.24 & -1.11 & 0.00 & (109) \\
\hline Pepper oil & 0.25 & -4.18 & -5.75 & 2.17 & 1.00 & (109) \\
\hline EOM & 1.2 & -5.07 & ND & ND & ND & (107) \\
\hline EOM & 1.2 & -7.34 & -0.2 & ND & ND & (107) \\
\hline
\end{tabular}

$\mathrm{EOM}=$ Essential oils mixture; $\mathrm{DMI}=$ Dry matter intake; VFA= Volatile fatty acids; $\mathrm{ND}=$ Not determined. ${ }^{1}=\mathrm{CH}_{4}=0.45$ (acetate) -0.275 (propionate) +0.4 (butyrate) ${ }^{(88)}$. 
en la cantidad y proporción de los AGV(76) Las modificaciones en el total y proporción de los AGV impacta sobre los perfiles de producción de metano, sobre todo si reduce la proporción de acetato y se incrementa la de propionato, por lo tanto cambios en estos repercutirán positiva o negativamente en la producción de metano. En los Cuadros 1, 2 y 3 se muestran los resultados de algunas investigaciones in vivo en las que se han evaluado la inclusión de diferentes $A E$, las dosis, sobre la respuesta en la producción de AGV totales en diferentes especies rumiantes. total VFA production and the acetate-propionate ratio (Tables 1, 2 and 3)(81).

Declines in in vitro methane production have been reported using different EO. When administered at $400 \mathrm{mg} / \mathrm{L}$, thymol, the main component derived from Thymus $v$. and Origanum v., consistently inhibited in vitro methane production but also lowered acetate and propionate concentrations(56). In another in vitro study using thymol, a dose of $900 \mathrm{mg} / \mathrm{L}$ mitigated methane production by $99 \%$ compared to a control(70). Methanogenesis is

Cuadro 2. Efecto de la adición de diferentes aceites esenciales y dosis sobre el consumo, promedio de ganancia diaria, metano y ácidos grasos volátiles totales en bovinos productores de carne, en diferentes estudios. Estimación de las diferencias porcentuales con respecto al testigo

Table 2. Effect of different essential oils and doses on dry matter intake, average daily weight gain, methanogenesis and total volatile fatty acids in beef cattle in selected studies. Percentages are the differences versus a control treatment

\begin{tabular}{lcccccc}
\hline & & & \multicolumn{2}{c}{ Methane } & Total & \\
Treatment & Dose g/d & DMI (\%) & WG (\%) & production (\%) & VFA (\%) & Ref. \\
\hline EOM & 1.0 & -0.82 & 2.84 & ND & ND & $(89)$ \\
EOM & 1.0 & -0.82 & 2.84 & ND & ND & $(89)$ \\
EOM & 1.09 & -1.65 & 3.97 & ND & ND & $(89)$ \\
EOM & 1.0 & 13.95 & ND & -13.83 & 14.65 & $(89)$ \\
EOM & 1.0 & 2.32 & ND & -9.86 & 8.69 & $(89)$ \\
Cinnemaldehyde & 0.4 & 10.30 & ND & -10.24 & 2.71 & $(102)$ \\
Cinnemaldehyde & 0.8 & 4.12 & ND & -3.09 & 1.64 & $(102)$ \\
Cinnemaldehyde & 1.6 & -10.30 & ND & -8.91 & 3.07 & $(102)$ \\
Cinnemaldehyde & 0.4 & 8.22 & 4.16 & ND & ND & $(107)$ \\
Cinnemaldehyde & 0.8 & 5.01 & -1.78 & ND & ND & $(107)$ \\
Cinnemaldehyde & 1.6 & -2.44 & -2.38 & ND & ND & $(107)$ \\
Eugenol & 0.4 & 1.59 & ND & ND & -1.06 & $(63)$ \\
Eugenol & 0.8 & 4.99 & ND & ND & -4.66 & $(63)$ \\
Eugenol & 1.6 & 2.55 & ND & ND & -6.14 & $(63)$ \\
EOM & 1.0 & -2.41 & -6.84 & -1.72 & -3.51 & $(5)$ \\
Cinnemaldehyde & 0.27 & -17.04 & ND & 9.77 & -2.61 & $(65)$ \\
Anise oil & 2.0 & 5.6 & ND & -12.69 & 0.25 & $(65)$ \\
Pepper oil & 1.0 & 9.21 & ND & -11.67 & -0.38 & $(65)$ \\
Cinnemaldehyde & 0.9 & 2.63 & ND & -11.34 & -1.41 & $(65)$ \\
Pepper oil & 0.5 & 10.66 & ND & -1.10 & -0.53 & $(129)$ \\
Anise oil & 0.5 & 2.66 & ND & -4.65 & -1.59 & $(129)$ \\
\hline
\end{tabular}

$\mathrm{EOM}=$ Essential oils mixture; $\mathrm{DMI}=$ Dry matter intake; $\mathrm{WG}=$ Average daily weight gain; $\mathrm{VFA}=$ Volatile fatty acids; $\mathrm{ND}=$ Not determined. ${ }^{1}=\mathrm{CH}_{4}=0.45$ (acetate) -0.275 (propionate) +0.4 (butyrate) ${ }^{(88)}$. 
Nitrógeno amoniacal. Como ya se ha mencionado, algunos $\mathrm{AE}$ inhiben a las bacterias generadoras de nitrógeno, por tanto la desaminación de las proteínas decrece, y se ha reportado hasta un $25 \%$ en la reducción de estas bacterias cuando se utilizó aceite de orégano de entre 30 y $300 \mathrm{mg} / \mathrm{L}(58,75)$. Es así como decrece la concentración de nitrógeno amoniacal en el rumen con el uso de $A E$, y puede favorece un flujo mayor de las proteínas al intestino delgado(77). Aunque este tipo de bacterias representa sólo el $1 \%$ del total de la población bacteriana en el rumen, poseen una actividad alta de desaminación(54,88). En otros estudios in vitro el nitrógeno amoniacal también decreció con aceite de canela de 15.6 a 7.8 mg/dL con dosis de aceite de 0.3 a 3,000 mg/L(79). also reduced with anethole at $20 \mathrm{mg} / \mathrm{L}(66), \mathrm{EO}$ from juniper berry at $20 \mathrm{mg} / \mathrm{L}$ and cinnamon at $250 \mathrm{mg} / \mathrm{L}^{(82)}$, and mint oil at $0.3,1$ and $3 \mathrm{ml} / \mathrm{L}$ rumen culture $(74,83)$. Cinnemaldehyde, the main active principle in cinnamon oil, reduces methane production by $94 \%$ at a $660 \mathrm{mg} / \mathrm{L}$ dose(68), likewise fennel and clove extracts lower methane production in vitro(61). Eucalyptus oil inhibits methanogenesis by $58 \%$ at a $1.66 \mathrm{ml} / \mathrm{L}$ $\alpha$-cyclodextrin-eucalyptus concentration(69), $90.3 \%$ at $2 \mathrm{ml} / \mathrm{L}$ and $70 \%$ at $330 \mathrm{mg} / \mathrm{L}^{(84)}$. Although a number of components have been identified in eucalyptus oil, p-cymene contributes most to lowering in vitro methane production(82).

Results have been mixed in in vivo trials. Studies using beef cattle have shown no decrease in

Cuadro 3. Efecto de la adición de diferentes aceites esenciales y dosis sobre el consumo, promedio de ganancia diaria, metano y ácidos grasos volátiles totales en ovinos, en diferentes estudios. Estimación de las diferencias porcentuales con respecto al testigo

Table 3. Effect of different essential oils and doses on dry matter intake, average daily weight gain, methanogenesis and total volatile fatty acids in sheep in selected studies. Percentages are the differences versus a control treatment

\begin{tabular}{lcccccc}
\hline & & & \multicolumn{2}{c}{ Methane $^{1}$} & Total & \\
Treatment & Dose g/d & DMI (\%) & WG (\%) & production (\%) & VFA (\%) & Ref. \\
\hline Cinnemaldehyde & 0.238 & 4.64 & 15.40 & -17.04 & 16.04 & $(70)$ \\
Garlic oil & 0.227 & -0.31 & 1.19 & -7.35 & 24.44 & $(70)$ \\
Juniper oil & 0.24 & 5.11 & 17.34 & -20.69 & 25.43 & $(70)$ \\
Diallyl disulphur & 4.61 & 0.26 & ND & 3.13 & -3.65 & $(97)$ \\
Lovastatin & 0.092 & 0.34 & ND & 2.48 & -5.43 & $(97)$ \\
Garlic oil & 5.31 & -5.85 & ND & 1.29 & -9.30 & $(98)$ \\
Diallyl disulphur & 2.19 & -2.92 & ND & -0.40 & -9.30 & $(98)$ \\
Garlic oil & $0.5^{*}$ & ND & ND & -4.45 & -0.66 & $(99)$ \\
Garlic oil & $0.5^{*}$ & ND & ND & -4.97 & 0.49 & $(99)$ \\
Garlic oil & $0.75^{*}$ & ND & ND & -5.40 & 0.66 & $(99)$ \\
EOM & 0.11 & ND & ND & 2.43 & -7.02 & $(122)$ \\
Carvacrol & 0.2 & -4.48 & 7.18 & -9.59 & 13.68 & $(66)$ \\
Cinnemaldehyde & 0.2 & 0.41 & 8.35 & -10.58 & 19.03 & $(66)$ \\
Carvacrol & 0.2 & 5.24 & 1.61 & -3.58 & 5.94 & $(66)$ \\
Cinnemaldehyde & 0.2 & 13.59 & 3.29 & 11.28 & 10.72 & $(66)$ \\
Cinnemaldehyde & 0.1 & 0.19 & -0.12 & 8.91 & -8.68 & $(117)$ \\
Cinnemaldehyde & 0.2 & 3.32 & 6.78 & -1.56 & -22.08 & $(117)$ \\
Cinnemaldehyde & 0.4 & 1.81 & -2.17 & -2.30 & -27.46 & $(117)$ \\
\hline
\end{tabular}

$\mathrm{EOM}=$ Essential oils mixture; $\mathrm{DMl}=$ Dry matter intake; $\mathrm{WG}=$ Average daily weight gain; $\mathrm{VFA}=$ Volatile fatty acids; ${ }^{*}$ g/kg dry matter; $\mathrm{ND}=$ Not determined. ${ }^{1}=\mathrm{CH}_{4}=0.45$ (acetate) -0.275 (propionate) +0.4 (butyrate) ${ }^{(88)}$. 
Sin embargo los resultados no fueron los mismos en estudios in vitro con anetol a $3 \mathrm{~g} / \mathrm{L}$, carvacrol y carvone a $300 \mathrm{mg} / \mathrm{L}(79)$. El guaiacol con concentraciones de 5 a 5,000 $\mathrm{mg} / \mathrm{L}$ baja la concentración de nitrógeno amoniacal hasta un 31.4 a $16.6 \%$ respectivamente, en relación con el testigo, mientras que el limoneno y timol con dosis de $50 \mathrm{mg} / \mathrm{L}$, y la vainillina y eugenol con dosis 500 mg/L no mostraron efectos en la concentración de nitrógeno amoniacal(80). Ya se ha mencionado que los efectos sobre las bacterias productoras de nitrógenos son dependientes del tipo y cantidad de proteína en la dieta(77).

\section{PERFILES DE PRODUCCIÓN DE METANO}

Los resultados en los que se ha evaluado la mitigación del metano como objetivo de la inclusión en las dietas de aceites esenciales son pocos e inconsistentes, y en algunos casos sólo se ha estimado la producción de metano en el rumen en base a la relación que tiene éste con el descenso en la producción total de AGV y la relación de acetato-propionato(81).

Se ha observado que el timol, mayor componente derivado del Thymus v. y Origanum v., a dosis de $400 \mathrm{mg} / \mathrm{L}$ inhibe consistentemente el metano in vitro, pero las concentraciones de acetato y propionato también decrecen(56). En otros trabajos in vitro también con timol a dosis de $900 \mathrm{mg} / \mathrm{L}$, observaron una mitigación en la producción del metano hasta un $99 \%$ en relación con el tratamiento testigo(70). También se han reportado disminución en la producción de metano con el anetol en dosis de $20 \mathrm{mg} / \mathrm{L}^{(66)}$. Otros $A E$ que disminuyen la metanogenesis son el $A E$ de vallas de enebro y el de canela en dosis de 20 y $250 \mathrm{mg} / \mathrm{L}$ respectivamente(82) , y aceite de menta con dosis de hasta 0.3, 1 y 2 $\mathrm{ml} / \mathrm{L}$ de medio de cultivo ruminal $(74,83)$.

El principal componente activo del aceite de canela es el cinemaldehido, el cual a dosis de $660 \mathrm{mg} / \mathrm{L}$ disminuye la producción de metano hasta en un $94 \%(68)$. Los extractos de hinojo y clavo también inhiben la producción de metano methane production using a commercial EO mixture administered at $1 \mathrm{~g} / \mathrm{d}$ for $25 \mathrm{~d}(5)$, or pine oil at an $8 \mathrm{mg} / \mathrm{L}$ dose(86). In a study using sheep, an oregano oil mixture at a $25 \mathrm{mg} / \mathrm{d}$ dose for $15 \mathrm{~d}$ lowered methanogenesis, and a series of other studies using different EO at different doses, including Anethum graveolens (32\% limonene), found a linear decline in methane production(87).

\section{EFFECT OF OE ON RUMINANT PRODUCTIVE PERFORMANCE}

Feed digestibility. The positive effects of EO on feed digestibility occur for two main reasons: 1) they reduce protein degradation in the rumen by inhibiting the growth of ammoniacal nitrogenproducing or proteolytic bacteria; and 2) they reduce starch degradation in response to inhibition of amylolytic microorganisms. Both these qualities favor protein and starch flow into the intestine(22). In a number of trials, addition of EO did not modify feed digestibility $(67,89,90)$. However, a $500 \mathrm{mg}$ dose of oregano oil resulted in high rumen protein concentration in sheep, but also affected total digestibility of other nutrients(91). In dairy cows, a $2 \mathrm{~g} / \mathrm{d}$ dose of juniper EO increased dry matter digestibility by $13 \%$ in 40:60 forage:concentrate diets. This effect could be due to an $11 \%$ increase in protein digestibility, but also to a slight increase in the digestibility of other nutrients(87). Very high doses of EO, however, lower DM digestibility probably because fiber digestibility decreases in the rumen $(5,63)$.

Rumen protein metabolism. Administering EO in ruminant diets decreases rumen ammoniacal nitrogen concentrations, thus lowering nitrogen excretion in the urine and feces. In earlier in vitro studies using a casein substrate and evaluating amino acid accumulation and ammoniacal nitrogen concentration in an in vitro rumen medium, a $1 \mathrm{~g} / \mathrm{L}$ dose of thymol lowered $\mathrm{N}$ production and diminished bacterial deamination(92). These results coincide with another study showing deamination inhibition and reduced ammoniacal nitrogen concentrations(93). 
in vitro(61). El aceite de eucalipto inhibe la producción de metano en un $58 \%$ con dosis de $1.66 \mathrm{~mL} / \mathrm{L}^{(69)}, 90.3 \%$ a $2 \mathrm{ml} / \mathrm{L}^{(84)}$, y $70 \%$ a $330 \mathrm{mg} / \mathrm{L}$ el aceite $\alpha$-ciclodextrinaeucalipto(84). Son varios los componentes identificados en el aceite de eucalipto(85), sin embargo el componente del aceite de eucalipto que más disminuye la producción de metano in vitro es el $p$-cimeno(82).

Estudios realizados con bovinos productores de carne en los que se usó una mezcla comercial de aceites esenciales (timol. eugenol, vainillina y limoneno) a $1 \mathrm{~g} / \mathrm{d}$, durante 25 días, no encontraron diferencias en la producción de metano en comparación con el tratamiento control(5), y tampoco se encontraron diferencias en estudios con aceite de pino a dosis de 8 $\mathrm{mg} / \mathrm{L}(86)$. En otros estudios se ha observado que la dosis de $25 \mathrm{mg} / \mathrm{d}$ de mezcla de aceite esencial de orégano en ovinos durante 15 días disminuye la producción de metano; también en estudios realizados con diferentes aceites esenciales y diferentes dosis de estos, así como con Anethum graveolens ( $32 \%$ limoneno) decrece linealmente la producción de metano(87). En los Cuadros 1, 2 y 3 se muestran los resultados de las investigaciones en las que se han evaluado in vivo la inclusión en las dietas con diferentes $A E$ y dosis en diferentes especies rumiantes, sobre la respuesta en la producción de metano con una estimación de este a partir de los perfiles molares de AGV(88).

\section{EFECTO EN EL COMPORTAMIENTO PRODUCTIVO DE RUMIANTES}

Digestibilidad del alimento. Los efectos positivos de la inclusión de aceites esenciales sobre la digestibilidad del alimento se dan por dos razones principalmente; primero, se reducen la degradación de la proteína en el rumen al inhibir la proliferación de bacterias productoras de nitrógeno amoniacal o proteolíticas, y segundo, se reduce la degradación de almidones como respuesta a la inhibición de microorganismos amilolíticos, favoreciendo en cantidad el flujo de estos dos nutrientes al intestino(22).
In a more recent study, a $9 \%$ decrease in deamination was observed in hydrolyzed casein incubated for $48 \mathrm{~h}$ with rumen liquid from cows fed a corn silage base diet and $1 \mathrm{~g} / \mathrm{d}$ dose of a commercial EO mixture(53). In another incubation study, deamination dropped by $24 \%$ in a $24 \mathrm{~h}$ in vitro incubation of rumen liquid from sheep administered a $110 \mathrm{mg} / \mathrm{d}$ of an EO mixture; this was largely due the negative effect of EO on selective populations of rumen bacteria(58). Populations of the $\mathrm{NH}_{3}-\mathrm{N}$ generating bacteria Clostridium sticklandii and Peptostreptococcus anaerobius are also reported to diminish in response to EO mixtures(53). In contrast, in vivo studies have not documented improved nitrogen flow into the intestine in sheep administered $110 \mathrm{mg} \mathrm{EO}$ and in dairy cows administered $2 \mathrm{~g}$ EO $(58,94)$.

Other factors related to protein use have been considered in studies of EO inclusion in ruminant diets, such as deamination and rumen protozoans with proteolytic activity(95). Protozoans also ingest large amounts of rumen bacteria which may slow microbial protein flow to the duodenum( $(96)$, however no studies have been done on the direct effects of EO on protozoan populations.

Neutral detergent fiber digestibility. High doses of clove and fennel extracts reduce activity of the enzymes carboxymethyl-cellulase and xylase (59). In an in vivo evaluation of diallyl disulphate and lovastatin as methane inhibitors in sheep, doses of 4 and $80 \mathrm{mg} / \mathrm{kg}$ DM changed neutral detergent fiber (NDF) digestibility, with a $14 \%$ increase caused by diallyl disulphate $(97)$. In another in vivo trial with sheep, this time evaluating the effect of garlic oil and diallyl disulphate (its main component) at doses of 2 and $5 \mathrm{~g} / \mathrm{mg}$ DM, organic matter digestibility improved $5.63 \%$ and NDF digestibility by $17.64 \%(98)$. A study including the effects of garlic oil (500 and $750 \mathrm{mg} / \mathrm{kg}$ ) and garlic powder (75 and $100 \mathrm{~g} / \mathrm{kg} \mathrm{DM}$ ) in sheep diets showed both NDF and acid detergent fiber digestibility to be negatively affected by the oil(99). 
En muchos de los estudios la digestibilidad del alimento no se modificó por AE $(67,89,90)$. Sin embargo otros estudios muestran que dosis de $500 \mathrm{mg}$ de aceite de orégano en ovinos repercute en una alta concentración de proteína a nivel ruminal, pero por otro lado se afectó la digestibilidad total de nutrientes(91). Reportes in vivo en vacas lecheras con dosis de aceite esencial de enebro de $2 \mathrm{~g} / \mathrm{d}$, mostraron un aumento en la digestibilidad de la materia seca en un $13 \%$ utilizando dietas con 40:60 forrajeconcentrado; estos investigadores explican que el efecto puede ser debido a que se incrementó la digestibilidad de la proteína de manera significativa en un $11 \%$, pero también puede deberse a un ligero incremento de digestibilidad de otros nutrientes(87). Sin embargo dosis altas de aceites esenciales decrecen la digestibilidad de MS, atribuible esto a la disminución de la digestibilidad de la fibra a nivel ruminal $(5,63)$.

Metabolismo de proteína en el rumen. Se ha reportado que al suministrar aceites esenciales en la alimentación de rumiantes se disminuyen las concentraciones de $\mathrm{N}$ amoniacal en el rumen, y por lo tanto la excreciones urinarias y fecales de éste. En los primeros trabajos in vitro observaron una disminución en la producción de $\mathrm{N}$ con la adición de timol a dosis de $1 \mathrm{~g} / \mathrm{L}$, usando caseína como substrato y evaluando la acumulación de aminoácidos y concentración de nitrógeno amoniacal, en el medio ruminal in vitro, observándose también una disminución en la desaminación bacteriana(92). Otro estudio mostró resultados similares de inhibición en la desaminación y concentraciones de nitrógeno amoniacal(93). Más recientemente se observó una disminución de la desaminación de un $9 \%$ con caseína hidrolizada incubada in vitro durante $48 \mathrm{~h}$ con liquido ruminal colectado de vacas alimentadas con ensilado de maíz como base, y con una dosis de $1 \mathrm{~g} / \mathrm{d}$ de una mezcla comercial de $A E^{(53)}$. Otro estudio reportó una disminución de $24 \%$ en la desaminación cuando se incubó in vitro caseína hidrolizada por $24 \mathrm{~h}$ con liquido ruminal obtenido de ovinos suplementados con una dosis de $110 \mathrm{mg} / \mathrm{d}$ de una mezcla de $\mathrm{AE}$, deduciendo el efecto negativo
Intake and weight gain. The effect of EO addition on the intake of ruminant diets depends on EO type and dose (Tables 2 and 3). No differences in intake have been reported using 0.75 and $2 \mathrm{~g} / \mathrm{d}$ of an EO mixture in cows $(59,100)$, $2 \mathrm{~g} / \mathrm{d}$ fennel oil in cows(87), $250 \mathrm{mg} / \mathrm{d}$ oregano oil in sheep(71), and 43 or $430 \mathrm{mg} / \mathrm{k} \mathrm{DM}$ in goats(67). Feed intake was negatively affected in studies of a $500 \mathrm{mg} / \mathrm{d}$ dose of cinnemaldehyde in dairy cattle(101), and a $500 \mathrm{mg} / \mathrm{d}$ cinnemaldehyde and $90 \mathrm{mg} / \mathrm{d}$ eugenol dose in beef cattle(65). This can be attributed to changes in palatability in different kinds of cattle feed with addition of high amounts of EO. In contrast, addition of 1 $\mathrm{mg} / \mathrm{d}$ pepper oil in concentrate for beef cattle stimulated intake and ruminal fermentation(65). Finally, a study using cinnemaldehyde in feed for bullocks showed that a dose of $400 \mathrm{mg} / \mathrm{d}$ increased feed intake by $10.3 \%$ but a higher dose of $1.6 \mathrm{~g} / \mathrm{d}$ had no effect.

Studies of weight gain in response to EO inclusion in the diet largely show no effect (Table 2 and 3). For example, no differences were observed in a study of daily weight gain in sheep fed a diet including oregano leaves at

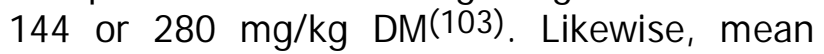
daily weight gain was unaffected in a study of beef cattle fed diets containing 2 or $4 \mathrm{mg} / \mathrm{d}$ of an EO mixture (thymol, eugenol, vanillin and limonene), although a quadratic effect was observed in feed conversion at a $2 \mathrm{~g} / \mathrm{kg}$ MS dose ${ }^{(94)}$. These studies coincide with other studies in which inclusion of EO had no effect on average daily weight gain(66).

Milk production and composition. Administration of EO to dairy cattle has produced mixed results in milk production and composition (Table 1). Addition of a commercial EO mixture (thymol, eugenol, vanillin and limonene) to diets for dairy cattle increased milk production(104). In another study, milk fat percentage was found to increase when dairy cattle were fed diets supplemented with a $500 \mathrm{mg} / \mathrm{d}$ per cow dose of an EO mixture (eugenol, geranium extract, and cilantro oil as the principal component)(90). A greater milk fat percentage was also reported in response to 
de los $A E$ sobre poblaciones selectivas de bacterias ruminales, principalmente(58). Se ha observado también una disminución en las bacterias generadoras de nitrógeno amoniacal (Clostridium sticklandii y Peptostreptococcus anaerobius) cuando se utilizan mezclas de $A E(53)$. Sin embargo estudios in vivo no han encontrado cambios a favor en el flujo de nitrógeno al intestino en ovinos y vacas productoras de leche cuando se usan dosis de $110 \mathrm{mg}$ y $2 \mathrm{~g}$ de mezcla de $\mathrm{AE}$, respectivamente $(58,94)$.

Existen otros factores que se relacionan con el aprovechamiento de la proteína y que se han contemplado en los estudios con la inclusión de $A E$ en dietas para rumiantes, como es el caso de los protozoarios ruminales que tienen actividad proteolítica y de desaminación(95). Por otra parte los protozoarios engullen bacterias ruminales en gran cantidad, y esto puede repercutir en lentificar el flujo de proteína microbiana al duodeno (96), pero no hay estudios sobre los efectos de los $A E$ y la población protozoaria directamente.

Digestibilidad de FDN. Se observó una disminución en la actividad de las enzimas carboxilmetil-celulasa y xilasa, con extractos de clavo e hinojo en altas concentraciones(59). Cuando se evaluaron dialil disulfito, y lovastatina como inhibidores de metano in vivo en ovinos, con dosis de 4 y $80 \mathrm{mg} / \mathrm{kg}$ de MS, se observaron diferencias en la digestibilidad de la FDN, tendiendo a incrementarse con dialil disulfito en un $14 \%(97)$. En otro estudio in vivo con ovinos se evaluó el efecto del aceite de ajo y su componente principal el dialil disufito en dosis de 2 y $5 \mathrm{~g} / \mathrm{kg}$ de $\mathrm{MS}$, encontrando mejoras en la digestibilidad de materia orgánica y FDN en un 5.63 y 17.64, respectivamente(98). Sin embargo con polvo de ajo y con aceite de ajo, en la alimentación de ovinos se encontró que la FDA y FDN fueron ligeramente afectadas negativamente en su digestibilidad con el polvo, no así con el aceite, a dosis de 75 y 100 g/ kg de MS de polvo(99). addition of $500 \mathrm{~g}$ oregano Origanum vulgare leaves in dairy cattle diets(105). A higher milk fat percentage may be due to changes in the proportions of VFA, acetate or the acetatepropionate ratio in response to EO inclusion, or to changes in energy contribution and better body condition due to improved feed quality(92). Addition of $16 \mathrm{mg} / \mathrm{L}$ of an EO mixture (thymol, eugenol, vanillin and limonene) in drinking water for dairy cattle raised milk production and its protein percentage but lowered the fat percentage (106). Other studies have found no differences in milk composition and production with inclusion of an EO mixture in the diet $(78,107-$ 110); this was even the case when $1 \mathrm{~g} / \mathrm{d}$ cinnemaldehyde was used(111).

High concentrations $(2 \mathrm{~g} / \mathrm{d})$ of an EO mixture are reported to increase linoleic acid concentration in milk fat, possibly due to inhibition of linoleic acid biohydrogenation in the rumen(100). Other studies have identified changes in VFA in the rumen, but not in the milk fatty acids profile in dairy cows and goats $(69,112)$. Some components of the EO included in ruminant diets may be present in the milk or meat(113-115), but it is still unclear to what degree these enrich product organoleptic and nutritional properties.

\section{EFFECTS ON IMMUNOLOGICAL CONDI- TION AND BLOOD METABOLITES}

Results from studies addressing the effect of EO on immune condition and blood metabolites have been mixed. In a study of immune condition in dairy cows fed diets supplemented with garlic and juniper oils, no differences were observed in white blood cell and haptoglobin counts(8). Addition of an EO mixture to dairy cattle feed also had no effect on blood metabolites such as glucose, non-esterified fatty acids (NEFA) and urea(108). A study using cinnemaldehyde at 144 and $288 \mathrm{mg} / \mathrm{kg} \mathrm{DM}$ in beef cattle also found no differences in white blood cells, amyloid A or lipopolysaccharides, but haptoglobin counts did decline as 
Consumo y ganancia de peso. Al igual que en muchos otros casos, la respuesta de la adición de $A E$ en dietas para rumiantes sobre el consumo depende también del tipo de aceite esencial y la dosis. Varios estudios realizados con 0.75 y $2 \mathrm{~g} / \mathrm{d}$ de mezcla de aceites esenciales $(59,100), 2 \mathrm{~g} / \mathrm{d}$ de aceite de hinojo en $\operatorname{vacas}(87), 250 \mathrm{mg} / \mathrm{d}$ de aceite de orégano en ovinos(71), y 43 o $430 \mathrm{mg} / \mathrm{k}$ de MS en $\operatorname{cabras}^{(67)}$ no mostraron diferencias en el consumo. En otros estudios con altas dosis de cinemaldehido $500 \mathrm{mg} / \mathrm{d}$ en vacas productoras de leche(101) mezcla de cinemaldehido $500 \mathrm{mg} / \mathrm{d}$ y eugenol $90 \mathrm{mg} / \mathrm{d}$ en bovinos productores de carne ${ }^{(65)}$, se observó afectado el consumo de alimento, lo cual puede ser atribuido a la palatabilidad que adquieren los diferentes tipos de alimentos para el ganado cuando se les adicionan cantidades altas de AE. En contraste, la adición de aceite de pimiento de $1 \mathrm{mg} / \mathrm{d}$ en concentrado en ganado productor de carne estimuló el consumo y la fermentación ruminal(65). Otro estudio demostró claramente que el cinemaldehido tiene efecto positivo en el consumo de alimento en $10.3 \%$ con dosis bajas de $400 \mathrm{mg} / \mathrm{d}$, pero que dosis altas de 1.6 $\mathrm{g} / \mathrm{d}$ el consumo se mantiene igual en comparación con el tratamiento control en novillos(102).

En estudios en los que se evaluó la ganancia diaria de peso en ovinos con inclusión en la dieta de hojas de orégano (144 o $280 \mathrm{mg} / \mathrm{kg}$ MS) no se observaron diferencias con respecto al tratamiento control(103); tampoco en estudios realizados con bovinos productores de carne, con dosis de 2 o $4 \mathrm{mg} / \mathrm{d}$ de una mezcla de aceites esenciales (timol, eugenol, vainillina y limoneno), ni en la media de ganancia diaria de peso con respecto al tratamiento control, pero se observó un efecto cuadrático sobre la conversión alimenticia con dosis de $2 \mathrm{~g} / \mathrm{kg}$ MS(94). Otros estudios tampoco encontraron diferencias con la inclusión del AE sobre el promedio de ganancia diaria de peso(66). En los Cuadros 2 y 3 se muestran los resultados de las investigaciones en las que se han evaluado la inclusión de diferentes AE y dosis, cinnemaldehyde dose increased(103). Reductions in haptoglobin have also been reported in beef cattle diets supplemented with 400 to 1,600 $\mathrm{mg} / \mathrm{d}$ eugenol(116). Differences in blood glycerol concentrations have been reported with administration of cinnemaldehyde in sheep(66). In addition, changes in NEFA and triglycerides concentrations have been observed in response to increasing doses (400 to $1600 \mathrm{mg} / \mathrm{d}$ ) of cinnemaldehyde in lambs, although no changes were observed in blood glucose and urea concentrations(63). In contrast, a study evaluating doses of 100, 200 and $400 \mathrm{mg} / \mathrm{kg}$ DM cinnemaldehyde in sheep found that only urea concentrations increased and only at the $200 \mathrm{mg} / \mathrm{kg}$ DM dose, and that NEFA, cholesterol and triglycerides concentrations exhibited no changes at any dose(117).

\section{DISCUSSION}

The last ten years have seen a rise in the number of studies addressing the potential benefits for production efficiency of including EO in ruminant diets. Many EO have positive effects on ruminal fermentation, methanogenesis mitigation and the digestibility of some ingredients. However, other EO still needs to be evaluated to identify optimum dose and feed system to provide benefits.

Caution is required when interpreting much of the data available to date indicating reduced methanogenesis with addition of EO because they were generated in vitro. This is vital since results often differ between in vitro and in vivo trials of the same compounds. Some EO have been shown to inhibit ammoniacal nitrogengenerating bacteria in vitro, but before antibiograms can be generated for specific EO further detailed study is required of their effects on other bacterial genera and populations, particularly methanogenic microorganisms. In vitro trials involve smaller microorganism populations than normally exist in the rumen, where survival conditions are ideal(118). In addition, doses in in vitro trials are given as $\mathrm{mg} / \mathrm{L}$, but would be more useful if expressed in 
en bovinos y ovinos, sobre el consumo y la ganancia promedio de de peso.

Producción y composición de la leche. Constan reportes en los que la adición de mezcla comerciales de $A E$ (timol. eugenol, vanillina y limoneno) ha incrementado la producción en ganado lechero(104). También que la alimentación con una mezcla de $\mathrm{AE}$ conteniendo eugenol, extracto de geranio y aceite de cilantro, como el mayor componente este último y en una dosis de $500 \mathrm{mg}$ por vaca por día incrementa el porcentaje de grasa en leche(90). Se ha reportado que la adición de $500 \mathrm{~g}$ de hojas de Origanum vulgare a las dietas de vacas también tiene efecto en el incremento de la grasa en leche (105). El incremento del porcentaje de grasa en leche puede deberse al cambio en la proporción de $\mathrm{AGV}$, acetato o proporción de acetato-propionato, que pueden modificarse con la inclusión de $A E(73,74)$, o por el cambio de aporte energético y el mejoramiento de la condición corporal por la mejoría en la alimentación(92). Diferentes resultados reportaron que cuando se adicionó una mezcla de aceites esenciales (timol. eugenol, vanillina y limoneno) en el agua de bebida en una dosis de $16 \mathrm{mg} / \mathrm{L}$, se incrementó la producción de leche y porcentaje de proteína, pero disminuyó el porcentaje de grasa(106). Otros estudios no han encontrado diferencias en la composición y producción de leche cuando se suministran mezclas de $A E$ en la dieta(78,107-110), ni con cinemaldehido a dosis de $1 \mathrm{~g} / \mathrm{d}(111)$. En el Cuadro 1 se muestran los resultados de las investigaciones en las que se han evaluado la inclusión de diferentes $\mathrm{AE}$ y dosis, en bovinos productores de leche y su efecto sobre la producción de leche.

Estudios(100) con una alta concentración de mezcla de $A E$ de $2 \mathrm{~g} / \mathrm{d}$ incrementó la concentración de ácido linoleico en la grasa de la leche, lo cual se puede deber a la inhibición de la biohidrogenación de éste en el rumen. Otros estudios muestran cambios de ácidos grasos volátiles en el rumen, pero no en los perfiles de ácidos grasos en leche en vacas y $\mathrm{mg} / \mathrm{g}$ incubated DM since variations exist under in vitro conditions in terms of the amount of dry matter versus the amount of culture medium used $(119,112)$. In vitro experimental periods are also generally quite short, preventing observation of any possible microorganism adaptation or resistance to $\mathrm{EO}(120,121,122)$. In short, the existing in vitro data now requires corroboration under in vivo conditions.

Future research will also need to address new EO sources and provide more detailed information on the EO used. Every region in the world has plants containing secondary components which are potential sources of new, more effective EO. In any EO, the active principle concentration can vary depending on the plant, variety, season and cultivation conditions, among others, meaning plant and extract EO profiles need to be evaluated and optimum extraction conditions determined(10,123). The EO profile of any extracted oil and identification of the main active principle modifying ruminal fermentation and any synergisms between components is extremely important for accurately evaluating their effects. More accuracy is also needed in reporting the dose of the active principle contributing to methanogenesis mitigation or ruminal fermentation modification, and $\mathrm{mg} / \mathrm{kg}$ DM doses need to be standardized in in vivo studies since daily feed intake varies widely by animal species(5).

To what extent EO mitigates methanogenesis is still unclear because those studies that include methane measurements are in vitro, methane production is not quantified in others, and very few in vivo studies of methanogenesis mitigation have been done because they are labor intensive and costly. One way of addressing this challenge is to estimate any mitigation using equations based on VFA production profiles(88).

There is also very little information on the effects of EO on some pathogens. Research has been done using some parasites, although studies are needed that involve nutrition and parasite factors $(123,124)$, as well as the antimicrobial 
cabras lecheras(69,112). Algunos componentes de los AE suministrados en dietas para rumiantes pueden estar presentes en la leche o carne de estos(113-115). Sin embargo, no se sabe hasta qué grado pueden enriquecer sus propiedades organolépticas y nutrimentales.

\section{EFECTOS EN EL ESTADO INMUNOLÓGICO Y ALGUNOS METABOLITOS SANGUÍNEOS}

Se han realizado estudios para evaluar también el estado inmunológico en vacas lecheras suplementadas con aceite de ajo y enebro, cuantificando los glóbulos blancos y la haptoglobulina, pero estos estudios no observaron diferencias(8). Se ha evaluado el efecto de la suplementación en vacas lecheras con una mezcla de $A E$ sobre algunos metabolitos en plasma como glucosa, ácidos grasos no esterificados (AGNE) y urea, sin encontrar tampoco diferencias significativas(108). En estudios con diferentes dosis de 144 y $288 \mathrm{mg}$ de cinemaldehido por kilogramo de MS en ganado cárnico, tampoco se observaron diferencias en glóbulos blancos, amiloide A sérico o lipopolisacáridos del plasma, pero se observó numéricamente un descenso conforme aumenta la dosis de cinemaldehido en haptoglobulina(103), y con eugenol suplementando ganado cárnico con dosis de 400 a $1600 \mathrm{mg} / \mathrm{d}$ también se ha observado reducción de haptoglobulina(116). Estudios en ovinos en los que se administró cinemaldehido, se encontraron diferencias en las concentraciones séricas de glicerol(66). También se han observado cambios cuadráticos en la concentración de AGNE y triglicéridos cuando se incrementa la dosis de cinemaldehido de 400 hasta $1,600 \mathrm{mg} / \mathrm{d}$ en bovinos cárnicos, pero no se observaron cambios en las concentraciones de glucosa o urea en el suero sanguíneo(63), es necesarios considerar la composición de la dieta y su efecto sinérgico con los AE. Cuando se evaluó el efecto de diferentes dosis de 100, 200 y $400 \mathrm{mg} / \mathrm{kg}$ de MS de cinemaldehido sobre algunos metabolitos sanguíneos en ovinos se reportó que solamente la urea en el plasma sanguíneo se incrementó effects of EO throughout the entire gastrointestinal tract(125-127).

What kinds of biohydrogenation processes EO may experience in the rumen and the influence EO addition may have on fatty acids biohydrogenation in the rumen is still unknown. Although some studies have evaluated milk chemical properties and EO presence in milk and meat(128), there is still insufficient data on the residual effects of EO in dairy and meat products and if these provide benefits in terms of physicochemical properties, product shelf-life and consumer health.

A final factor to consider is the cost/benefit analysis of EO use in livestock systems. Essential oils extraction and the resulting concentrations often translate into high use costs. In some cases, reduced methanogenesis under in vitro conditions requires increasing doses, implying that higher doses would also be needed for in vivo studies. This could result in high production costs and undesired changes in feed palatability. One possible option would be EO administration via controlled release devices in the rumen. $A$ wide variety of studies have been done addressing the effect of EO in livestock systems, but they have not led to clear conclusions due to a diverse array of EO doses, different active principle profiles in EO that modify ruminal fermentation and a lack of data on the effect diet characteristics may have on essential oils effectiveness(129).

End of english version

con dosis de $200 \mathrm{mg} / \mathrm{kg}$ de MS, sin observar cambios en AGNE, colesterol o triglicéridos(117).

\section{DISCUSIÓN}

En la última década se han realizado estudios con el objetivo de conocer y explotar los beneficios de la inclusión en las dietas para rumiantes de AE para mejorar la eficiencia en 
la producción. Algunos de los AE tienen efectos positivos sobre la fermentación ruminal, mitigación del metano, y digestibilidad de algunos nutrientes, sin embargo algunos otros aun deben de ser evaluados en cuanto a las dosis y los sistemas de alimentación apropiados para su uso.

Primeramente se debe de mencionar que muchas de las investigaciones en las que se ha observado una disminución en la producción de metano cuando se adiciona $A E$ han sido realizadas in vitro, y se debe de tener cuidado en la interpretación de estos estudios pues en muchos de los casos no se obtienen los mismos resultados en condiciones in vivo. Aunque algunos $A E$ inhiben a las bacterias generadoras de nitrógeno amoniacal en los experimentos in vitro, aún falta evaluar más detalladamente los efectos de estos sobre otros géneros 0 poblaciones bacterianas, y más puntualmente sobre los microorganismos metanógenos, precisando con esto el antibiograma de los AE. Hay que considerar también que bajo condiciones in vitro las poblaciones de microorganismos son menores a las normalmente encontradas en el rumen, donde además éstas cuentan con un máximo de confort de sobrevivencia(118). En condiciones in vitro las dosis son en $\mathrm{mg} / \mathrm{L}$, éstas deben de ser expresadas preferentemente en $\mathrm{mg} / \mathrm{g}$ de MS incubada, pues también hay variaciones de las condiciones in vitro con la cantidad de materia seca que se experimenta en relación con la cantidad del medio de cultivo $(119,112)$. Se debe considerar también en condiciones in vitro los tiempos de evaluación, que generalmente son cortos y en muchos de los casos no se logra observar un posible efecto de adaptación o resistencia de los microorganismos a los $\operatorname{AE}(120,121,122)$. Se deben de corroborar los datos in vitro con los in vivo.

Existen plantas en cada región que deben de ser consideradas para la evaluación de otras fuentes de este tipo de componentes secundarios, que pudieran ser nuevos y ofrecer mejores resultados. Considerar también que la concentración del principio activo en los $\mathrm{AE}$ puede variar dependiendo de la planta, variedad, época del año y condiciones de cultivo, y por ende se deben realizar análisis de los perfiles de $\mathrm{AE}$ en los extractos o plantas a evaluar, así como considerar mejor el proceso de extracción $(10,123)$, de igual manera considerar el perfil de AE que contenga el aceite, así como evaluaciones para determinar el principal principio activo modificador de la fermentación ruminal o el sinergismos entre estos. Con respecto a esto también es necesario que se reporte la dosis del principio activo al que se atribuye el afecto mitigante de metano o modificador de los perfiles de fermentación ruminal, y estandarizar las dosis de $\mathrm{mg} / \mathrm{kg}$ de MS en trabajos in vivo pues el consumo varía por día por animal(5).

Con respecto al metano, en algunas investigaciones se han realizado mediciones pero bajo condiciones in vitro; en otros no se ha cuantificado éste, por lo cual aún es poca la producción científica para aseverar que los $\mathrm{AE}$ mitigan la producción de metano; aunado a esto, las investigaciones in vivo sobre los efectos de mitigación de la producción de metano son menores, puesto que en estos casos son laboriosas y costosas. Sin embargo se pueden realizar estimaciones por medio de ecuaciones en base a los perfiles de producción de AGV(88).

Tampoco existe suficiente información de los efectos sobre algunos patógenos, aunque existen investigaciones realizadas sobre algunos parásitos, habría que considerar estudios que incluyan los factores nutrición y parásito(123,124). De igual manera los efectos antimicrobianos en todo el tracto gastrointestinal(125-127).

No se tiene aun suficiente información sobre los procesos de biohidrogenación a los que se pueden someter estos $\mathrm{AE}$ en el rumen, o la influencia de la adición de estos sobre la biohidrogenacion de ácidos grasos en el rumen. Aunque se han realizado estudios evaluando las propiedades químicas de la leche y la presencia de estos AE en la leche(128) y carne, 
no hay suficiente evidencia del efecto residual de estos en la leche o productos cárnicos, y si éste pudiera tener beneficios sobre las propiedades químico físicas y sobre la vida de anaquel de los productos, o en la salud del consumidor.

Aunque no menos importante, un factor más a considerar es el costo/beneficio del uso de estos nuevos productos, pues en muchos de los casos, la extracción y las concentraciones en que estos se encuentran resultan en un costo elevado. Además en algunos casos la concentración de $\mathrm{AE}$ en las que se observa disminución de la metanogénesis ha sido con dosis altas in vitro, e in vivo implicaría concentraciones altas también y posiblemente costos elevados de producción con el uso del producto, así como cambios en la palatabilidad del alimento; no obstante, una opción en algunos casos sería la fabricación de dispositivos con AE de liberación controlada en el rumen. Aunque existe gran variedad de estudios aún son poco concluyentes debido a que las dosis del $A E$ son muy diversas, el perfil de los principios activos modificadores de la fermentación ruminal de los $A E$ también es variable en cada uno de ellos, y otro aspecto bastante importante es la respuesta que se obtiene según las características de la dieta con la que se realizan las evaluaciones(129).

\section{LITERATURA CITADA}

1. Steinfeld H, Gerber P, Wassenaar T, Castel V, Rosales M, De Haan C. Livestock's Long Shadow: Environmental issues and options. FAO 2006; Rome, Italy.

2. Johnson KA, Johnson DE. Methane emissions from cattle. J Anim Sci 1995; (73):2483-2492.

3. Boadi D, Benchaar C, Chiquette J, Masse D. Mitigation strategies to reduce enteric methane emissions from dairy cows: update review. Can J Anim Sci 2004; (84):319-335.

4. Nevel CJ, and Demeyer DL. Control of rumen methanogenesis. Environ Monitor Assess 1996; (42):73-79.

5. Beauchemin KA, McGinn SM, McAllister TA. Dietary mitigation of enteric methane from cattle. CAB Rev. Perspect Agric Vet Sci Nutr Nat Resour 2009;4:1-18.

6. OJEU Regulation (EC) No 1831/2003 of the European Parliament and the Council of 22 September 2003 on additives for use in animal nutrition. Official J Eur Union
2003; Page:L268/36 in OJ EU of 10/18/2003. Brussels, Belgium.

7. Cowan MM. Plant products as antimicrobial agents. Clin Microbiol Rev 1999;(12):564-582.

8. Chao SC, Young DG. Screening for inhibitory activity of essential oils on selected bacteria, fungi and viruses. J Essent Oil Res 2000;(12):639-649.

9. Greathead H. Plant and plant extract for improving animal productivity. P Nutr Soc 2003; (62):279-290.

10. Burt S. Essential oils: their antibacterial properties and potential applications in foods-A review. Int J Food Microbiol 2004; (94) 223-253.

11. Simon JE, Essential oils and culinary herbs. In: Janick J, Simon JE, editors. Advances in new crops. Portland, Oregon: Timber Press; 1990:472-483.

12. Gershenzon J, Croteau R. Terpenoids in herbivores: Their Interactions with secondary plant metabolites. Rosenthal GA, Berenbaum MR editors. San Diego, CA: Academic Press; 1991; (1): 165-219.

13. Vokou D, Kokkini S, Bessiere JM. Geographic variation of Greek oregano (Origanum vulgare ssp. hirtum) essential oils. Biosc Biotech Bioch 1993; (21):287-295.

14. Cosentino S, Tuberoso ClG, Pisano B, Satta M, Mascia V, Arzedi $E$, et al. In vitro antimicrobial activity and chemical composition of Sardinian thymus essential oil. Lett Appl Microbiol 1999; (29):130-135.

15. Dorman HJD, Deans SG. Antimicrobial agents from plants: antibacterial activity of plant volatile oils. J Appl Microbiol 2000; (88): 308-316.

16. Delaquis RJ, Stanich K, Girard B, Massa G. Antimicrobial activity of individual and mixed fractions of dill, cilantro, coriander and eucalyptus essential oils. Int J Food Microbiol 2002; (74): 101-109.

17. Martinez S, Madrid J, Hernandez F, Megias MD, Sotomayor JA, J ordan MJ. Effect of thyme essential oils (Thymus hyemalis and Thymus zygis) and monensin on in vitro ruminal degradation and volatile fatty acid production. J Agric Food Chem 2006;(54):6598-6602.

18. Wink M, Schimmer $O$. Modes of action of defensive secondary metabolites. In: Wink M editor. Functions of plant secondary metabolites and their exploitation in biotechnology. Sheffield UK: Sheffield Academic Press; 1999;17-112.

19. Sangwan NS, Farooqi AHA, Shabih F, and Sangwan RS. Regulation of essential oil production in plants. J Plant Growth Regul 2001;(34):3-21.

20. McNaughton SJ, Tarrants JL, McNaughton MM, Davis RH. Silica as a defense against herbivory and a growth promotor in African grasses. Ecology 1985; (66) 528-535.

21. Marriott BM. Functional foods: an ecologic perspective. Am J Clin Nutr 2000; (71):1728S-1734S.

22. Hart KJ, Yañez-Ruiz DR, Duvel SM, McEwan NR, Newbold. Plant extracts to manipulate rumen fermentation. Anim Feed Sci Tech 2008; (147):8-35.

23. Dewick PM. Medicinal natural products: A biosynthetic approach. 2nd ed. Chichester, UK: John Wiley and Sons Ltd; 2002.

24. Amagase $H$, Petesch $B L$, Matsuura $H$, Kasuga $S$, Itakura $Y$. Intake of garlic and its bioactive components. J Nutr 2001; (31): 955S-962S. 
25. Amagase $\mathrm{H}$. Clarifying the real bioactive constituents of garlic. J Nutr 2006;(136):716S-725S.

26. Jones MG, Hughes J, Tregova A, Milne J, Tomsett AB, Collin, HA. Biosynthesis of the flavour precursors of onion and garlic. J Exp Bot 2004;(55):1903-1918.

27. Corzo-Martinez M, Corzo N, Villamiel M. Biological properties of onions and garlic. Trends Food Sci Tech 2007;(18):609625.

28. Bode $H$, Müller R. Possibility of bacterial recruitment of plant genes associated with the biosynthesis of secondary metabolites. Plant Physiol 2003;(132):1153-1161.

29. Harborne JB, Williams CA. Advances in flavonoid research since 1992. Phytochemistry 2000;(55):481-504.

30. Reddy L, Odhav B, Bhoola KD. Natural products for cancer prevention: A global perspective. Pharmacol Therap 2003; (99): 1-13.

31. Trouillas P, Calliste CA, Allais DP, Simon A, Marfak A, Delage C, Duroux JL. Antioxidant, anti-inflammatory and antiproliferative properties of sixteen water plant extracts used in the Limousin countryside as herbal teas. Food Chem 2003; (80): 399-407.

32. Gutiérrez ME, García AF, Madariaga MA, Sagrista ML, Casado FJ, Mora M. Interaction of tocopherols and phenolic compounds with membrane lipid components: Evaluation of their antioxidant activity in a liposomal model system. Life Sci 2003; (72):2337-2360.

33. Lee SE, Hwang HJ, Ha JS, J eong HS, Kim JH. Screening of medicinal plant extracts for antioxidant activity. Life Sci 2003; (73): 167-179.

34. Hoffmann C, Evans CA. The use of spices as preservatives. J Ind Eng Chem 1911;(3)835-838.

35. Davidson PM, Naidu AS. Phyto-phenols. In: Natural food antimicrobial systems. Naidu AS editor. Boca Raton, FL: CRC Press; 2000:265-293.

36. Griffin SG, Wyllie SG, Markham JL, Leach DN. The role of structure and molecular properties of terpenoids in determining their antimicrobial activity. Flavour Frag J 1999; (14): 322-332.

37. Sikkema J, Bont JAM, Poolman B. Interactions of cyclic hydrocarbons with biological membranes. J Biol Chem 1994; (269): 8022-8028.

38. Ultee A, Kets EP, Smid EJ. Mechanisms of action of carvacrol on the food-borne pathogen Bacillus cereus. Appl Environ Microb 1999; (65):4606-4610.

39. Cox SD, Mann CM, Markam JL. Interaction between components of the essential oil of Melaleuca alternifolia. J Appl Microbiol 2001;(91):492-497.

40. Juven BJ, Kanner J, Schved F, and Weisslowicz H. Factors that interact with the antibacterial action of thyme essential oil and its active constituents. J Appl Bacteriol 1994; (76): 626-631.

41. Gustafson RH, Bowen RE. Antibiotic use in animal agriculture. J Appl Microbiol 1997;(83):531-541.

42. Prescott LM, Harley JP, Klein DA. Control de microorganismos por agentes físicos y químicos. In. Microbiologýa. Madrid, Spain: McGraw-Hill-Interamericana de España 2004:145162.

43. Münchberg U, Anwar A, Mecklenburg S, J acob C. Polysulfides as biologically active ingredients of garlic. Org Biomol Chem 2007; (5): 1505-1518.
44. Fujisawa $H$, Watanabe $K$, Suma $K$, Origuchi $K$, Matsufuji $H$, Seki T, Ariga T. Antibacterial potential of garlic-derived allicin and its cancellation by sulfhydryl compounds. Biosci Biotech Bioch 2009; (73): 1948-1955.

45. Smith-Palmer A, Stewart J, Fyfe L. Antimicrobial properties of plant essential oils and essences against five important food-borne pathogens. Lett Appl Microbiol 1998;(26):118122.

46. Cimanga K, Kambu K, Tona L, Apers S, Bruyne T, Hermans N, Totte J L, Pieters, Vlietinck AJ. Correlation between chemical composition and antibacterial activity of essential oils of some aromatic medicinal plants growing in the Democratic Republic of Congo. J Ethnopharmacol 2002; (79): 213-220.

47. Helander IM, Alakomi H, Latva-Kala K, Mattila-Sandholm T, Pol I, Smid EJ, Gorris LGM, Wright A. Characteritzation of the action of selected essential oil components on gramnegative bacteria. J Agric Food Chem 1998; (46):3590-3595.

48. Nikaido $\mathrm{H}$. Prevention of drug access to bacterial targets: permeability barriers and active efflux. Science 1994; (264): 382-388.

49. Reuter HD, Koch JP, Lawson L. Therapeutic effects and applications of garlic and its preparations. In: Garlic: The science and therapeutic application of Allium sativum $\mathrm{L}$. and related species. Koch HP. Lawson LD editors. Williams \& Wilkins, Baltimore, MD. 1996.

50. O'Gara EA, Hill DJ, Maslin DJ. Activities of garlic oil, garlic powder, and their diallyl constituents against Helicobacter pylori. Appl Environ Microbiol 2000;(66):2269-2273.

51. Ross ZM, O'Gara EA, Hill DJ, Sleightholme HV, and Maslin DJ. Antimicrobial properties of garlic oil against human enteric bacteria: Evaluation of methodologies and comparisons with garlic oil sulfides and garlic powder. Appl Environ Microb 2001;(67):475-480.

52. Busquet $M$, Calsamiglia S, Ferret A, Carro MD, Kamel C. Effect of garlic oil and four of its compounds on rumen microbial fermentation. J Dairy Sci 2005; (88):4393-4404.

53. McIntosh FM, Williams P, Losa R, Wallace RJ, Beever DA, Newbold CJ. Effects of essential oils on ruminal microorganisms and their protein metabolism. Appl Environ Microb 2003; (69):5011-5014.

54. Wallace RJ. Antimicrobial properties of plant secondary metabolites. Proc Nutr Soc 2004;(63):621-629.

55. Patra AK, Saxena J. Dietary phytochemicals as rumen modifiers: a review of the effects on microbial populations. Anton Leeuwe Int J G 2009;(96):363-375.

56. Evans D, Martin SA. Effects of thymol on ruminal microorganisms. Current Microbiol 2000; (41):336-340.

57. McKay DL Blumberg JB. A review of the bioactivity and potential health benefits of chamomile tea (Matricaria recut ita L.). Phytother Res 2006;(20)519-530.

58. Newbold CJ, Mcintosh FM, Williams P, Losa R, Wallace RJ. Effects of a spesific blend of essential oil compounds on rumen fermentation. Anim Feed Sci Tech 2004;(114):105112.

59. Benchaar C, Chaves AV, Fraser GR, Yang $Y$, Beauchemin KA, McAllister TA. Effects of essential oils and their components on I $\mathrm{n}$ vitro rumen microbial fermentation. Can J Anim Sci 2007; (87):413-419.

60. Fraser GR, Chaves AV, Wang Y, McAllister TA, Beauchemin $\mathrm{KA}$, Benchaar C. Assessment of the effects of cinnamon 
leaf oil on rumen microbial fermentation using two continuous culture systems. J Dairy Sci 2007;(90):23152328.

61. Patra AK, Kamra DN, Agarwal N. Effects of extracts of spices on rumen methanogenesis, enzyme activities, and fermentation of feeds in vitro. J Sci Food Agr 2010; (90):511-520.

62. Mohammed N, Ajisaka N, Lila ZA, Mikuni K, Hara K, Kanda $\mathrm{S}$, Itabashi $\mathrm{H}$. Effect of J apanese horseradish oil on methane production and ruminal fermentation in vitro and in steers. J Anim Sci 2004; (82):1839-1846.

63. Yang WZ, Ametaj BN, Benchaar C, Beauchemin KA. Dose response to cinnamaldehyde supplementation in growing beef heifers: Ruminal and intestinal digestion. J Anim Sci 2010; (88): 680-688.

64. Ando S, Nishida T, Ishida M, Hosoda K, Bayaru E. Effect of peppermint feeding on the digestibility, ruminal fermentation and protozoa. Livest Prod Sci 2003; (82):245-248.

65. Cardozo PW, Calsamiglia S, Ferret A, Kamel C. Effects of alfalfa extract, anise, capsicum and a mixture of cinnamaldehyde and eugenol on ruminal fermentation and protein degradation in beef heifers fed a high-concentrate diet. J Anim Sci 2006; (84):2801-2808.

66. Chaves AV, Stanford K, Gibson LL, McAllister TA, Benchaar C. Effects of carvacrol and cinnamaldehyde on intake, rumen fermentation, growth performance and carcass characteristics of growing lambs. Anim Feed Sci Tech 2008;(145):396408.

67. Malecky M, Broudiscou LP, Schmidely P. Effects of two levels of monoterpene blend on rumen fermentation, terpene and nutrient flows in the duodenum and milk production in dairy goats. Anim Feed Sci Tech 2009;(154):24-35.

68. Macheboeuf D, Morgavi DP, Papon Y, Mousset JL, ArturoSchaan M. Dose-response effects of essential oils on in vitro fermentation activity of the rumen microbial population. Anim Feed Sci Tech 2008; (145):335-350.

69. Kumar R, Kamra DN, Agrawal N, Chaudhary LC. Effect of eucalyptus (Eucalyptus globules) oil on in vitro methanogenesis and fermentation of feed with buffalo rumen liquor. Anim Nutr Feed Tech 2009; (9):237-243.

70. Chaves AV, Stanford K, Dugan MER, Gibson LL, McAllister TA, Van Herk F, Benchaar C. Effects of cinnamaldehyde, garlic and juniper berry essential oils on rumen fermentation, blood metabolites, growth performance and carcass characteristics of growing lambs. Livest Sci 2008;(117):215224.

71. Wang CJ, Wang SP, Zhou H. Influences of flavomycin, ropadiar and saponin on nutrient digestibility, rumen fermentation and methane emission from sheep. Anim Feed Sci Tech 2009; (148):157-166 .

72. Castillejos L, Calsamiglia S, Ferret A. Los R. Effects of a specific blend of essential oil compounds and the type of diet on rumen microbial fermentation and nutrient flow from a continuous culture system. Anim Feed Sci Tech 2005; (119): 29-41.

73. Benchaar C, Petit HV, Berthiaume R, Ouellet DR, Chiquette $J$, Chouinard PV. Effects of essential oils on digestion, ruminal fermentation, ruminal microbial populations, milk production and milk composition in dairy cows fed alfalfa silage or corn silage. J Dairy Sci 2007;(90):886-897.

74. Agarwal N, Shekhar RC, Kumar LC, Chaudhary, Kamra DN. 2009. Effect of peppermint (Mentha piperita) oil on in vitro methanogenesis and fermentation of feed with buffalo rumen liquor. Anim Feed Sci Tech 2009; (148):321-327.

75. Cardozo PW, Calsamiglia S, Ferret A, Kamel C Screening for the effects of natural plant extracts at different $\mathrm{pH}$ on in vitro rumen microbial fermentation of a high concentrate diet for beef cattle. J Dairy Sci 2005; (83):2572-2579.

76. Spanghero $M$, Zanfi $C$, Fabbro E, Scicutella N, Camellini $C$. Effects of a blend of essential oils on some end products of in vitro rumen fermentation. Anim Feed Sci Tech 2008; (145): 364-374.

77. Wallace RJ, McEwan NR, Mclntosh FM, Teferedegne B, Newbold CJ. Natural products as manipulators of rumen fermentation. Asian-Aust. J Anim Sci 2002;(15):1458-1468.

78. Russell JB, Strobel HJ, Chen G. Enrichment and isolation of a ruminal bacterium with a very high specific activity of ammonia production. Appl Environ Microb 1988;(54):872877.

79. Busquet M, Calsamiglia S, Ferret A, Kamel C. Plant extracts affect in vitro rumen microbial fermentation. J Dairy Sci 2006; (89): 761-771.

80. Castillejos L, Calsamiglia S, Ferret A, Effect of essential oils active compounds on rumen microbial fermentation and nutrient flow in in vitro systems. J Dairy Sci 2006; (89):26492658.

81. Patra AK. Meta-analyses of effect of phytochemicals on digestibility and rumen fermentation characteristics associated with methanogenesis. Sci Agri 2010;(90):27002708.

82. Chaves AV, He ML, Yang WZ, Hristov AN, McAllister TA, Benchaar C. Effects of essential oils on proteolytic, deaminative and methanogenic activities of mixed ruminal bacteria. Can J Anim Sci 2008; (89):97-104.

83. Tatsouka N, Hara K, Mlkuni K, Hara K, Hashimoto H, Itabashi $\mathrm{H}$. Effects of the essential oil cyclodextrin complexes on ruminal methane production in vitro. Anim Sci J 2008; (79):68-75.

84. Sallam SMA, Bueno ICS, Brigide P, Godoy PB, Vitti DMSS, and Abdalla AL. Efficacy of eucalyptus oil on in vitro rumen fermentation and methane production. Options Mediterraneennes 2009; (85):267-272.

85. Bhatti HQ, Iqbal Z, Chatha SAS, Bukhari LH. Variations in oil potential and chemical composition of Eucalyptus crebra among different districts of Punjab-Pakistan. Int J Agric Bioi 2007; (9): 136-138.

86. Soliva CR, Widmer $\mathrm{S}$, and Kreuzer M. Ruminal fermentation of mixed diets supplemented with St. J ohns Wort (Hypericum perforatum) flowers and pine (Pinus mugo) oil or mixtures containing these preparations. J Anim Feed Sci Tech 2008; (17):352-362.

87. Yang WZ, Benchaar C, Ametaj BN, Chaves AV, He ML, McAllister TA. Effects of garlic and juniper berry essential oils on ruminal fermentation and on the site and extent of digestion in lactating cows. J Dairy Sci 2007;(90):56715681.

88. Moss AR, Jouany J, Newbold J. Methane production by ruminants: its contribution to global warming. Ann Zoo 2000; (49): 231-253.

89. Meyer NF, Erickson GE, Klopfenstein TJ, Greenquist MA, Luebbe MK, Williams P, Engstrom MA. Effect of essential oils, tylosin and monensin on finishing steer performance, carcass characteristics, liver abscesses, ruminal fermentation and digestibility. J Anim Sci 2009;(87):2346-2354. 
90. Santos MB, Robinson PH, Williams P, Losa R. Effects of addition of an essential oil complex to the diet of lactating dairy cows on whole tract digestion of nutrients and productive performance. Anim Feed Sci Tech 2010; (157):64-71.

91. Kozelov L, Tliev F, Profirov J, Nikolov IVS, Ganev G, Modeva T, Krasteva M. The effect of supplementing sheep with Ropadiar on digestibility and fermentation in the rumen. Zhivotnov Dni Nuki 2001;(3):152-154.

92. Borchers R. Proteolytic activity of rumen fluid in vitro. J Anim Sci 1965; (24): 1033-1038.

93. Broderick GA, Balthrop JE. Chemical inhibition of amino acid deamination by ruminal microbes in vitro. J Anim Sci 1979; (49): 1101-1111.

94. Benchaar C, Duynisveld JL, Charmley E. Effects of monensin and increasing dose levels of a mixture of essential oil compounds on intake, digestion, and growth performance of beef cattle. Can J Anim Sci 2006;(86):9196.

95. Williams AG, Coleman GS. The rumen protozoa. New York, NY, USA. Springer-Verlag; 1992.

96. Ivan $M$, Neill $L$, Forster $R$, Alimon $R$, Rode $L M$, Entz $T$. Effects of Isotricha, Dasytricha, Entodinium, and total fauna on ruminal fermentation and duodenal flow in wethers fed different diets. J Dairy Sci 2000;(83):776-787.

97. Kelvenhusen F, Meile L, Kreuzer M, Soliva CR. Effects of monolaurin on ruminal methanogens and selected bacterial species from cattle, as determined with the rumen simulation technique. Anaerobe 2011;(17):232-238.

98. Klevenhusen F, Zeitza J O, Duvalb S, Kreuzera M, Solivaa CR. Garlic oil and its principal component diallyl disulfide fail to mitigate methane, but improve digestibility in sheep. Anim Feed Sci Tech 2011;(166-167):356-363.

99. Anassori E, Bahram DN, Rasoul P, Akbar T, Siamak AR, Masoud M, Safa FA, Parviz F. Garlic: A potential alternative for monensin as a rumen Modifier. Livest Sci [in press] 2011doi: 10.1016/j.livsci.2011.08.003.

100. Benchaar C, Petit HV, Berthiaume R, Whyte TD, Chouinard PY. Effects of addition of essential oils and monensin premix on digestion, ruminal fermentation, milk production and milk composition in dairy cows. J Dairy Sci 2006; (89): 43524364.

101. Busquet M, Greathead H, Calsamiglia S, Ferret A, Kamel C. Efecto del extracto de ajo y el cinemaldehido sobre la producción, composición y residuos en leche en vacas de alta producción. TEA 2003; (24):756-758.

102. Yang WZ, Ametaj BN, Benchaar C, He ML, Beauchemin KA. Cinnamaldehyde in feedlot cattle diets: Intake, growth performance, carcass characteristics and blood metabolites. J Anim Sci 2010;(88):1082-1092.

103. Bampidis VA, Christodoulou V, Florou-Paneri P, Christaki E, Spais AB, Chatzopoulou PS. Effect of dietary dried oregano leaves supplementation on performance and carcass characteristics of growing lambs. Anim Feed Sci Tech 2005; (121): 285-295.

104. Kung J rL, Williams P, Schmidt RJ, Hu W. A blend of essential plant oils used as an additive to alter silage fermentation or used as a feed additive for lactating dairy cows. J Dairy Sci 2008; (91): 4793-4800.

105. Tekippe J, Hristov A, Heyler AN, Cassidy KS, Zheljazkov TW, Ferreira VDS, Karnati JF, Varga GA. Rumen fermentation and production effects of Origanum vulgare L. leaves in lactating dairy cows. J Dairy Sci 2011; (94):5065-5079.

106. Mossaad AES, Ramadan AS, Saad IAS. Influence of essential oils supplementation on digestion, rumen fermentation, rumen microbial population and productive performance on fairy cows. Asian. J Anim Sci 2009;(3):112.

107. Tassoul MD, Shaver RD. Effect of a mixture of supplemental dietary plant essential oils on performance of periparturient and early lactation dairy cows. J Dairy Sci 2009;(92): 17341740.

108. Zjderveld SM, Newbold JR, Perdok HB. Methane mitigation potential of a garlic derivative, yucca powder and calcium fumarate in dairy cattle. Provimi Res Innov Centre, Brussels, Belgium. Wageningen University, Wageningen, the Netherlands. 2009.

109. Tager LR, Krause KM. Effects of essential oils on rumen fermentation, milk production, and feeding behavior in lactating dairy cows. J Dairy Sci 2011;(94):2455-2464.

110. Zjderveld SM, Dijkstra J, Perdok HB, Newbold JR, Gerrits WJJ. Dietary inclusion of diallyl disulfide, yucca powder, calcium fumarate, an extruded linseed product, or medium-chain fatty acids does not affect methane production in lactating dairy cows. J Dairy Sci 2011; (94):3094-3104.

111. Benchaar C, McAllister TA, Chouinard PY. Digestion, ruminal fermentation, ciliate protozoal populations, and milk production from dairy cows fed cinnamaldehyde, quebracho condensed tannin, or Yucca schidigera saponin extracts. J Dairy Sci 2008; (91):4765-4777.

112. Benchaar C, Chouinard PY. Short communication: Assessment of the potential of cinnamaldehyde, condensed tannins and saponins to modify milk fatty acid composition of dairy cows. J Dairy Sci 2009; (92):3392-3396.

113. Molnar A, Lemberkovices E, Spiller S. Detection of caraway and chamomile components in goat milk. Tejqazdasaq 1997; (57): 22-27.

114. Chion AR, Tabacco E, Giaccone D, Peiretti PG, Battelli G, Borreani G. Variation of fatty acid and terpene profiles in mountain milk and Toma piemontese cheese as affected by diet composition in different seasons. Food Chern 2010; (121):393-399.

115. Noni ID, Battelli G. Terpenes and fatty acid profiles of milk fat and Bitto cheese as affected by transhumance of cows on different mountain pastures. Food Chern 2008; (109) : 299-309.

116. Yang WZ, Ametaj BN, He ML, Benchaar C, Beauchemin KA. Cinnamaldehyde in feedlot cattle diets: intake, growth performance, carcass characteristics, and blood metabolites. J Anim Sci 2010;(88):1082-1092.

117. Chaves AV, Dugan MER, Stanford K, Gibson LL, Bystrom J M, McAllister TA, Van-Herk F, Benchaar C. A dose-response of cinnamaldehyde supplementation on intake, ruminal fermentation, blood metabolites, growth performance, and carcass characteristics of growing lambs. Livest Science 2011 doi: http://dx. doi.org/10.1016/j.livsci.2011.06.006.

118. Chow JM, Van-Kessel JAS, Russell JB. Binding of radiolabeled monensin and lasolacid to ruminal microorganisms and feed. J Anim Sci 1994;(72):16301635. 
119. Benchaar C, Calsamiglia S, Chaves AV, Fraser GR, Colombatto D, McAllister TA, Beauchemin KA. A review of plant-derived essential oils in ruminant nutrition and production. Anim Feed Sci Tech 2008; (145):209-228.

120. Cardozo PW, Calsamiglia S, Ferret A, Kamel C. Effects of natural plant extracts on ruminal protein degradation and fermentation profiles in continuous culture. J Anim Sci 2004; (82):3230-3236.

121. Molero R, I bara M, Calsamiglia S, Ferret A, Losa R. Effects of a specific blend of essential oil compounds on dry matter and crude protein degradability in heifers fed diets with different forage to concentrate ratios. Anim Feed Sci Tech 2004; (114): 91-104.

122. Castillejos L, Calsamiglia S, Ferret A, Losa R. Effects of dose and adaptation time of a specific blend of essential oils compounds on rumen fermentation. Anim Feed Sci Tech 2007; (132): 186-201.

123. Sivropoulou A, Papanikolaou E, Nikolaou C, Kokkini S, Lanaras T, Arsenakis M. Antimicrobial and cytotoxic activities of Origanum essential oils. J Agric Food Chem 1996; (44): 1202-1205.

124. Vidal F, Vidal JC, Gadelha APR, Lopes CS, Coelho MGP, Monteiro-Leal LH. Giardia lamblia: the effects of extracts and fractions from Mentha piperita Lin. (Lamiaceae) on trophozoites. Exp Parastiol 2007;(115):25-31.
125. Olson ME, O'Handley RM, Ralston BJ, McAllister TA, Thompson RCA. Update on Cryptosporidiumand Giardia infections in cattle. Trends Parsitol 2004;(20):185-191.

126. Burt SA, Reinders RD. Antibcaterial activity of selected plant essential oils against Escherichia coli O157:H7. Lett Appl Microbiol 2003;(36):162-167.

127. Friedman $M$, Henika PR, Levin CE, Mandrell RE. Antibacterial activities of plant essential oils and their components against Escherichia coli 0157: $\mathrm{H} 7$ and Salmonella enterica in apple juice. J Agric Food Chem 2004; (52):6042-6048.

128. Oussalah M, Caillet S, Saucier L, Lacroix M. Inhibitory effects of selected essential oils on the growth of four pathogenic bacteria: E. coli O157:H7, Salmonella typhimurium, Staphylococcus aureus and Listeria monocytogenes. Food Control 2007;(18):414-420.

129. Fandiño I, Calsamiglia S, Ferret A, Blanch M. Anise and capsicum as alternatives to monensin to modify rumen fermentation in beed heifers fed a high concentrate diet. Anim Feed Sci Tech 2008; (145):409-417.

130. Klevenhusen F, Muro-Reyes A, Khiaosa-ard R, MetzlerZebeli BU, Zebeli Q. A meta-analysis of effects of chemical composition of incubated diet and bioactive compounds on in vitro ruminal fermentation. Anim Feed Sci Tech 2012; (176):61-69. 
